RUNNING HEAD: Meta-Analytic Review of Leader Group Prototypicality

\title{
Advancing the Social Identity Theory of Leadership: A Meta-Analytic Review of Leader Group Prototypicality
}

Niklas K. Steffens1,*, Katie A. Munt1, Daan van Knippenberg2, Michael J. Platow3, S. Alexander Haslam 1

1 The University of Queensland, Brisbane, QLD 4072, Australia

2 Drexel University, Philadelphia, PA 19104, USA

3 Australian National University, Canberra, ACT 2691, Australia

* Corresponding author: Niklas K. Steffens, School of Psychology, The University of

Queensland, Brisbane, QLD 4072, Australia; Tel: + (0) 613364 9555; Email:

n.steffens@uq.edu.au

Accepted (uncorrected) version for publication in Organizational Psychology Review. This paper is not the copy of record and may not exactly replicate the final version of the article.

\section{Acknowledgments}

We thank Nerisa Dozo and Carissa Adams for help with data coding and analyses. This research was supported by grants (DE180100676) and (FL110100199) from the Australian Research Council awarded to first and fifth author. 


\begin{abstract}
This research advances a social identity approach to leadership through a meta-analysis examining four novel hypotheses that clarify the nature and impact of leader group prototypicality (the extent to which a leader is perceived to embody shared social identity). A random-effects meta-analysis $(k=128, N=32,834)$ reveals a moderate-to-large effect of prototypicality that holds across evaluative and behavioral outcomes. The effect is stronger (a) when prototypicality is conceptualized as the ideal-type rather than the average group member, (b) for stronger prototypes (indexed by group longevity), and (c) for group members in formal rather than non-formal leadership roles. The effect is not contingent on group prototypicality entailing differentiation from other (out)groups. Additionally, results provide meta-analytic evidence of widely examined key factors: follower group identification (which enhances the relationship) and leader group-serving behavior (which attenuates the relationship). Building on these findings, we outline the implications for the next wave of theoretical and empirical work.
\end{abstract}

Keywords: self \& identity; intergroup relations; groups/teams; leadership 
Leadership has long been a focus for research in the field of group and organizational behavior, with most researchers seeking to address the core question of what makes leaders effective. In this context, leadership effectiveness is generally conceptualized as leaders' capacity to motivate and mobilize followers in ways that advance group and organizational goals (Haslam, Reicher \& Platow, 2015; House, Javidan, \& Dorfman, 2001; van Knippenberg, 2012; van Vugt, Hogan, \& Kaiser, 2008). A key feature of this conceptualization is that leadership is ultimately about the achievement of collective rather than personal goals. Moreover, leadership takes place in the context of group membership that is shared between leaders and their followers (i.e., as members of the same team, department, business unit, or organization) and this group membership in turn affects followers' responses to the leader — so that leadership effectiveness is determined, at least in part, by followers' perceptions of the degree to which the leader is seen as a member of their group with whom they share social identity (Hogg, 2001; van Knippenberg \& Hogg, 2003). Even though a number of theories recognize the importance of groups and teams (e.g., Dinh et al., 2014), the social identity theory of leadership is unique in that it is built around the idea that leadership is based on social identity-based perceptions of the leader as a group member (Haslam \& Platow, 2001; Hogg, 2001; van Knippenberg \& Hogg, 2003). Historically, researchers have acknowledged the importance of shared social identity for group functioning (Lord, Brown, \& Freiberg, 1999; Shamir, House, \& Arthur, 1993; van Knippenberg, van Knippenberg, De Cremer, \& Hogg, 2004), yet in recent years an increasing number of researchers have studied social identity dynamics as the basis of leadership in ways proposed by social identity theorizing (for a review, see Epitropaki, Kark, Mainemelis, \& Lord, 2017).

The social identity theory of leadership argues that leadership effectiveness centers on leaders and followers seeing themselves as part of a common group (i.e., as sharing a social identity, a sense of 'we and us'). It argues that key to individuals' openness to each other's 
influence is seeing themselves and others not just in terms of personal identities (as 'I' and 'you') but also in terms of a shared social identity (as 'we' and 'us'). Building on this, scholars have argued that leaders' capacity to influence others is contingent on leaders' engagement with a social identity that is shared by leaders and followers. While leaders' engagement with shared identity can take different forms (Haslam et al., 2011; van Dick et al., 2018), the proposition that has received most attention in the research literature suggests that leaders will be more effective to the extent that they are seen as prototypical of an ingroup and hence embody what it means to be 'one of us'. Centering on the notion of leader group prototypicality (e.g., Hogg, 2001; Platow \& van Knippenberg, 2001), this proposition is different from the notion of leader prototypicality as used in work on implicit leadership theories (e.g., Epitropaki, Sy, Martin, Tram-Quon, \& Topakas, 2013; Lord, Foti, De Vader, 1984). While the latter refers to the degree to which a person is seen to be representative of the more general category of leaders, the former refers to the extent to which a leader is seen to the representative of a specific group (e.g., a work team, an organization, a political group) that leaders and followers share — and perceive themselves to share — membership of. This perception that the leader represents a shared social identity (a sense of 'we' and 'us') that is shared with followers has a range of consequences (Haslam, Reicher \& Platow, 2011; Hogg \& van Knippenberg, 2003; Turner, 1991). In particular, it engenders trust in the leader (Giessner \& van Knippenberg, 2008) and gives the leader a basis to influence group members (van Knippenberg \& Wilke, 1992), in ways that generally increase leadership effectiveness. Recent reviews point to a growing body of research that provides empirical support for this proposition and the broader tenets of a social identity approach to leadership (Barreto \& Hogg, 2017; Epitropaki et al., 2017; Haslam, Reicher, \& Platow, 2011; Hogg, van Knippenberg, \& Rast, 2012; Steffens et al., 2014; van Dick et al., 2018; van Knippenberg, 2011). Nevertheless, despite this growing body of evidence, there are four conceptual 
ambiguities surrounding the theory's core concept of leader group prototypicality that are reflected in the way researchers conceptualize prototypicality: (a) whether prototypicality refers to an ideal-typed group member or the average group member, (b) whether prototypicality necessarily entails differentiation from other groups, (c) whether variation in prototype strength (i.e., how well the mental representation of the group is developed) is consequential for leadership outcomes, and (d) and whether influence of leader group prototypicality is contingent on a leader having a formal leader role (vs. a non-formal leader role). Development of the social identity theory of leadership requires us to resolve these ambiguities. To do so, in this paper we develop and test four hypotheses that address these ambiguities and then subject these hypotheses to a meta-analytic test — thereby capitalizing on variation in research practice that relates to these conceptual ambiguities.

The first of these hypotheses relates to the fact that leader group prototypicality can be understood as a representation of the group as it currently is perceived to be, or as a representation of what the group aspires to be (i.e., an average-type or an ideal-type representation). We argue that aspirations - goals, aims, ambitions — are an integral part of group members' social identities, and are more closely intertwined with the influence of leader group prototypicality (van Knippenberg \& Hogg, 2003) than the more descriptive elements of the group "as it currently is". Accordingly, we hypothesize that leader group prototypicality will be more strongly related to leadership outcomes when it captures the ideal-type of the group and not only the average-type of current attributes.

Second, self-categorization theory (Turner, Hogg, Oakes, Reicher, \& Wetherell, 1987), on which the social identity theory of leadership draws heavily, suggests that leader group prototypicality can be understood not only in terms of within-group commonalities (i.e., what group members have in common) but also with reference to between-group differences (i.e., comparisons that differentiate the ingroup from other groups). Research 
practice varies, however, in the extent to which this intergroup comparative context is captured (explicitly or implicitly) in the conceptualization of leader group prototypicality. In line with self-categorization theory, we hypothesize that leader group prototypicality will be more strongly related to leadership outcomes when it is defined with reference to both within-group similarities and between-group differences rather than only within-group similarities.

Third, group prototypes are mental representations, and groups can be expected to differ in how well-developed these mental representations are. We refer to such differences in how clearly defined in group members' minds the group prototype is as differences in prototype strength. We argue that stronger prototypes should make responses to leadership more contingent on leader group prototypicality, and accordingly expect that the effects of leader group prototypicality will be more pronounced to the extent that group prototypes are strong. That said, prototype strength is hard to measure directly and so this has not been explored in prior research. Nevertheless, self-categorization theory's principle of perceiver readiness - which argues that prior experience is a key determinant of categorization (Oakes, Haslam, \& Turner, 1994) — suggests group longevity should be a reasonable proxy for prototype strength. This is a core attribute on which groups differ (Hollenbeck, Beersma, $\&$ Schouten, 2012) and we would expect members of more enduring groups to have stronger group prototypes than members of short-lived groups. On this basis, we hypothesize that the effects of leader group prototypicality will be stronger for members of more enduring groups (vs. members of more short-lived groups).

Fourth, group prototypicality has been linked to the influence not only of individuals who are in formal leader positions but also those in non-formal leader positions (Fielding \& Hogg, 1997; van Knippenberg, van Knippenberg, \& van Dijk, 2000). This begs the question of whether the formal leader role affects the influence of leader group prototypicality. That is, 
does it matter whether leader group prototypicality relates to a leader in a formal rather than a non-formal leader position? We argue that formal leadership positions entail role expectations and obligations to the group that render the leader's representativeness of the group more salient, and hence that the effects of leader group prototypicality will generally be stronger for leaders in formal than in non-formal roles.

Our study advances the social identity theory of leadership by proposing and testing these four hypotheses and thereby providing greater theoretical clarity regarding the theory's core concept of leader group prototypicality. In addition, we seek to build on and consolidate previous research by conducting meta-analytical tests of two moderators that have been identified as core to the social identity theory of leadership: follower group identification, which is argued to be associated with stronger effects of leader group prototypicality (Hogg, 2001; Hains, Hogg, \& Duck, 1997), and leader group-serving behavior, which should attenuate the effect of leader group prototypicality (van Knippenberg \& Hogg, 2003; van Knippenberg \& van Knippenberg, 2005). Finally, we aim to provide a more precise understanding of the impact of leader group prototypicality on leader outcomes by providing an assessment that encompasses the entire body of existing research evidence (Cumming, 2014; Schmidt \& Oh, 2016) while also exploring the potential influence of publication bias (Banks, Kepes, \& McDaniel, 2012; Kepes, Banks, McDaniel, \& Whetzel, 2012).

\section{Theoretical Background}

The social identity approach, comprising social identity and self-categorization theories (Ashforth \& Mael, 1989; Brewer, 1979; Hogg \& Terry, 2000; Tajfel \& Turner, 1979, Turner et al., 1987), posits that people can derive a sense of self not only from what makes them unique and special as individuals (their personal identity; a sense of "I"), but also from their membership in a social group and their communalities with other group members (their social identity; a sense of "we"). This insight is important because researchers have argued 
and shown that people's internalization of a group as part of their self-concept is a basis for a range of key group and organizational behaviors (Ashforth, Harrison, \& Corley, 2008;

Haslam, 2001; Hogg \& Terry, 2000; Turner, 1982). These include cooperation and helping (Blader \& Tyler, 2009), motivation and performance (van Knippenberg, 2000), learning and modeling (Mavor, Platow, \& Bizumic, 2017), and health and well-being (Haslam, Jetten, Postmes, \& Haslam, 2009; for meta-analytic reviews, see Lee, Park, \& Koo, 2015; Ng, 2015; Riketta \& van Dick, 2005; Steffens, Haslam, Schuh, Jetten, \& van Dick, 2017). They also include leadership and social influence (Ellemers, de Gilder, \& Haslam, 2004; Haslam et al., 2011; Hogg \& van Knippenberg, 2003; Reicher, Haslam, \& Hopkins, 2005; Steffens et al., 2014; Turner, 1991; van Knippenberg et al., 2004).

The social identity theory of leadership builds on the insight that leadership effectiveness is also contingent on shared social identity between leader and followers (Hogg, 2001; Turner \& Haslam, 2001; van Knippenberg \& Hogg, 2003). The core proposition of this theory that has guided more than two decades of research (after Turner, 1991) is that a leader should be more influential the more followers perceive him or her to be prototypical of the shared social identity. This notion of leader group prototypicality rests on the concept of a group prototype - group members' mental representations of the nature of their group (i.e., "who we are"). As noted above, in capturing group identity, the group prototype can reflect that identity not just in descriptive terms but also in aspirational terms. The group prototype thus captures the shared social reality of the group: shared norms, beliefs, and values, as well as shared aspirations, ambitions, and goals (Turner et al., 1987). Group prototypicality, then, captures the extent to which a given group member is perceived to embody the group prototype - the shared social reality associated with the group's social identity. Accordingly, leaders serve as a psychological anchor for other members to the extent that they represent the shared social reality of the group by embodying the collective sense of self 
(i.e., "we") that is important to these other group members (Haslam et al., 2011; Hogg \& van Knippenberg, 2003; Steffens et al., 2014; van Knippenberg, 2011).

Several narrative reviews have summarized the empirical evidence for the proposition that leader group prototypicality is positively related to indicators of leadership outcomes (e.g., Hogg et al., 2012; Platow, Haslam, Reicher, \& Steffens, 2015). For instance, when leaders are seen as group prototypical, they receive stronger support from followers (Platow \& van Knippenberg, 2001; Ulrich, Christ, \& van Dick, 2009), are regarded as more fair (De Cremer, van Dijke, \& Mayer, 2010; Lipponen, Koivisto, \& Olkkonen, 2005), are trusted more (Giessner \& van Knippenberg, 2008; Kalshoven \& Den Hartog, 2009), are regarded as more charismatic (Platow, van Knippenberg, Haslam, van Knippenberg, \& Spears, 2006; Steffens, Haslam, \& Reicher, 2014), and inspire higher performance (Li, Chiaburu, Kirkman, \& Xie, 2013; van Knippenberg \& van Knippenberg, 2005). There is also evidence from a previous meta-analysis that there is a positive relationship between leader group prototypicality and two subjective evaluations of leadership: trust in, and support for, the leader (Barreto \& Hogg, 2017). Although this analysis is informative, and instills confidence in the reliability of the basic relationship between leader group prototypicality and follower responses, its scope was limited to examination of these two outcomes as they were reported in published studies (comprising only a quarter of the independent samples identified by the present analysis). Moreover, this more limited scope did not afford the opportunity to examine the moderation hypotheses we advance in the current study, and limited the ability of the analysis to further develop the social identity theory of leadership. In the following sections, we develop the arguments underlying the hypotheses outlined above. As well as providing greater conceptual clarity around the core concept of leader group prototypicality, this analysis also paves the way for future theoretical and empirical development. 


\section{Leader Group Prototypicality as the Average vs. Ideal Group Member}

The concept of prototypicality has its origins in categorization theory where it is used primarily to refer to non-human categories (e.g., animals, objects; Rosch, 1978). In the social identity approach the concept of group prototypicality has been applied to human groups (Turner et al., 1987). This introduces an important deviation from its use for non-human groups. For most practical purposes, prototypes of non-human groups can be understood to capture the typical or average group member — they are most similar to other members and descriptive of the group as it is (perceived to be). For human groups, in contrast, prototypes also capture an ideal or aspirational element that includes attributes such as future-oriented goals and ambitions. To a certain extent, goals and ambitions also capture what it is that guides group members' attitudes and behavior. Importantly, however, goals and ambitions also speak to what we strive for and in that sense reflect the ideal-type of the group positive deviations from the typical or average group member. For human groups, group prototypes thus should not be understood in purely descriptive terms - who we are — but also in aspirational terms - who we would ideally be (as with collective possible selves; Stam, Lord, van Knippenberg, \& Wisse, 2014; van Knippenberg et al., 2004). These ideas also resonate with ideas put forward about implicit leadership theories (e.g., Epitropaki et al., 2013; Junker \& van Dick, 2014) that distinguish between average and ideal prototypes of leaders in general. Even though research on implicit leadership theories does not concern leader group prototypicality, and thus does not concern the distinction between average and ideal-type group prototypical leaders, it provides more general support for the idea that we can form categories (e.g., whether these pertain to leaders or social groups more generally) based on more average or ideal representatives of that category.

Accordingly, considerations of leader group prototypicality have emphasized this normative and aspirational quality (Steffens et al., 2014; Steffens, Haslam, Ryan \& Kessler, 
2013; van Knippenberg, 2011). Importantly, however, others have understood leader group prototypicality as referring to the typical or average group member rather than to such an ideal-type (e.g., Halevy, Berson, \& Galinsky, 2011), in part because of its origins in categorization theory where for non-human groups the distinction is less relevant. Nevertheless, this raises the question of whether an understanding of leader group prototypicality that includes the aspirational, ideal-type aspect is more strongly related to leadership outcomes than an understanding that only reflects a more descriptive, average member notion of group prototypicality. As noted above, we predict that this is likely to be the case, because goals and aspirations capture not necessarily how things are but beliefs about how things could be (and, more specifically, who we want to be) that provides the basis for leaders' capacity to mobilize followers' energies and hence their effectiveness. These beliefs are therefore important in guiding group members' attitudes and behaviors.

Although there has been no direct test of this reasoning within the leader group prototypicality literature, our current analysis aligns closely with work on deviance and adherence to in-group norms (e.g., Crane \& Platow, 2010; Packer, 2008). A critical component of this latter work lies in the distinction between descriptive and injunctive norms (e.g., Cialdini, Kallgren, \& Reno, 1991). Much like our distinction between descriptive and aspirational group prototypes, descriptive norms reflect what group members are doing, while injunctive norms are more aspirational, describing what group members approve of doing. Across three studies with both pre-existing and laboratory-created groups, Crane and Platow (2010) observed that participants who self-categorized as group members were more likely to align their behaviors with injunctive than descriptive norms. Indeed, these group members were willing to deviate from descriptive group norms to align themselves with the injunctive, aspirational group norms. 
Accordingly, we hypothesize that these aspirational elements will be more closely aligned with leaders' ability to motivate group members to pursue group objectives:

H1. Leader group prototypicality will be more strongly associated with leadership outcomes for conceptualizations of group prototypicality that capture the prototype as an ideal rather than an average group member.

\section{Leader Group Prototypicality as Implicitly vs. Explicitly Capturing Intergroup Context}

The very notion of a social group implies an intergroup context where membership in a group derives its meaning in part from the fact that other people do not belong to the group (Turner et al., 1987). The conceptualization of group prototypicality captures this in so far as the group prototype reflects not only what group members have in common but also what distinguishes their group from other groups (Postmes, Haslam, \& Swaab, 2005; Turner et al., 1987). From this perspective, an operationalization of leader group prototypicality would capture not only perceptions that a leader is representative of attributes that are shared by ingroup members but also that the leader is representative of those things that distinguish the ingroup from other outgroups.

A review of the literature suggests that studies vary in this respect, with some operationalizing prototypicality explicitly with reference to the intergroup comparative context (i.e., how the group differs from other groups; e.g., Cicero, Bonaiuto, Pierro, \& van Knippenberg, 2008, Study 2; Koivisto, Lipponen, \& Platow, 2013, Study 2; Pierro, Cicero, \& Higgins, 2009: Study 2; Platow \& van Knippenberg, 2001), but others operationalizing prototypicality in ways that are non-comparative in terms of the intergroup context (e.g., De Cremer et al., 2010, Study 1; Giessner, van Knippenberg, \& Sleebos, 2009, Study 1; Leicht, Randsley de Moura, \& Crisp, 2014). This is an issue that is closely connected to the concept of leader group prototypicality. Accordingly, addressing whether such conceptual differences are consequential is not just a methodological matter, but also speaks to theoretical issues 
related to the psychology of prototypicality perception (i.e., whether or not this is enhanced by intergroup comparison).

One reading of these differences in operationalization is that they are largely inconsequential because there always is an implicit intergroup comparison when defining a group prototype. That is, what group members have in common is, at least in part, what distinguishes them from members of other groups (i.e., so that these are not separate elements but necessarily interlinked). Another reading could be that non-comparative operationalizations may include characteristics that are not seen to be related to what makes the group distinctive, and therefore are less impactful in driving social influence. This reading would see explicit distinctiveness as a key element of group identity (cf. Brewer, 1991; Turner, 1985) such that conceptualizations which are comparative in intergroup terms more accurately capture leader group prototypicality. This latter reading leads us to hypothesize that:

H2. Leader group prototypicality will be more strongly associated with leadership outcomes when conceptualizations of group prototypicality capture the prototype in intergroup comparative terms rather than non-comparative terms.

\section{Leader Group Prototypicality and Prototype Strength (Indexed by Group Longevity)}

The group prototype is not an objective given, but reflects group members' mental representation of the group (Turner et al., 1987). Such mental representations differ in the extent to which they are well-developed and clear in perceivers' minds (Oakes et al., 1994; Turner et al., 1994). We conceptualize such variations in the extent to which group members' mental representations of group identity are well-developed as variations in prototype strength. For some groups, members will have a better, more developed understanding of what the group identity is - a stronger group prototype - than is the case for others. Selfcategorization theory would suggest that group longevity is one fundamental determinant of 
these differences in prototype strength. In line with this point, group longevity has been observed to be one of the fundamental characteristics that differentiates between social and organizational groups (Hollenbeck et al., 2012). At one extreme, there are short-lived groups that exist for such a limited period of time that they do not really have a history or significant time horizon into the future (e.g., student teams working on a course assignment or a team put together for one short-term project). At the other extreme, there are social groups that have existed for decades or even for hundreds of years and that have a long horizon into the future, as is the case for many organizations and a range of societal groups. Such differences in group longevity are a core basis for differences in prototype strength, because it takes time for a stable and well-developed prototype to emerge (Reicher \& Hopkins, 2001; Sani, 2007; Shamir, House, \& Arthur, 1993).

Accordingly, even though there are, to our knowledge (based on the search reported below), no studies of leader group prototypicality that have directly assessed prototype strength, for reasons outlined above, we can use differences in the longevity of the groups that have been studied as a proxy for prototype strength — while also acknowledging that proxies of this form allow only for an initial indirect test of the influence of the construct of interest. In this context, it is apparent that studies of leader group prototypicality have relied on groups of varying longevity. For example, some laboratory experiments have relied on ad hoc groups that have had no prior interaction (e.g., De Cremer et al., 2010: Study 1; Giessner \& van Knippenberg, 2008: Studies 1-2 and 4) and short-lived groups in the field (e.g., Fielding \& Hogg, 1997), whereas others have studied leadership in pre-existing and ongoing groups in the field (e.g., Hirst, van Dick, \& van Knippenberg, 2009; Lipponen et al., 2005; Sluss, Ployhart, Cobb, \& Ashforth, 2012) and in the laboratory (e.g., Platow \& van Knippenberg, 2001; Platow et al., 2006). Across these studies, we hypothesize that: 
H3. Leader group prototypicality will be more strongly associated with leadership outcomes in groups that have stronger prototypes, as indexed by group longevity.

\section{Leader Group Prototypicality of Members in Formal vs. Non-Formal Leader Positions}

The study of leadership is not limited to people who have formal leadership roles (i.e., those with senior positions in formal organizational hierarchies) but also includes people who have non-formal leadership roles (e.g., Fransen et al., 2014; Hollander \& Julian, 1969; Shamir \& Howell, 1999; Wheelan \& Johnston, 1990). Research informed by the social identity theory of leadership has included studies of the impact of leader group prototypicality on the effectiveness of both leaders in formal and non-formal leadership positions (e.g., Fielding \& Hogg, 1997; van Knippenberg et al., 2000) and does not make formal distinctions concerning the impact of leader group prototypicality for these two types of leaders. Nevertheless, we would argue that a formal (vs. a non-formal) leader role should have a bearing on the impact of leader group prototypicality as a consequence of the expectations and obligations that people associated with formal leader roles. Formal leader roles put individuals in positions where they are expected by subordinates to fulfill leadership functions associated with the group (e.g., to initiate and organize group activities, to coordinate members), but these same expectations are likely to be less strong for people in non-formal roles. Moreover, as a function of its structural (hierarchical) legitimacy, it is also possible that a formal leadership position will be more directly associated with subordinates' expectations that the leader should be representative of the group.

Such role expectations should affect the salience of formal and non-formal leaders' group prototypicality. Formal leaders are more likely to stand in the spotlight and act on behalf of the group in interactions with other groups, which should make evaluations of their group prototypicality particularly salient for followers and mean that leader group prototypicality has a stronger bearing on followers' responses. This is not to say that group 
prototypicality would not influence the leadership effectiveness of non-formal leaders; theory and evidence suggests it does (e.g., Fielding \& Hogg, 1997); rather the issue is that leader group prototypicality should exert a stronger influence on the effectiveness of formal leaders. On this basis we hypothesize that:

H4. Leader group prototypicality will be more strongly associated with leadership outcomes for members in formal than in non-formal leadership positions.

\section{Follower Group Identification and Leader Group-Serving Behavior as Widely Examined Moderators of Leader Group Prototypicality Effects}

Early accounts of the social identity theory of leadership suggested two key moderating influences of leader group prototypicality effects: follower social identification with the group and leader group-oriented behavior (van Knippenberg \& Hogg, 2003). First, because leader group prototypicality revolves around shared group membership, it has been argued that the influence of group prototypicality should be more pronounced to the extent that followers identify with the group (Hogg, 2001). By way of example, members of a team should care little about whether or not the leader embodies what the team is about if psychologically they fail to see themselves as a member of the group. But they are likely to be more sensitive to the leader's representativeness of the team when that team is an important part of their identity.

Second, leader group prototypicality and leader group-serving behavior have been proposed to interact such that the one substitutes for the other (van Knippenberg \& Hogg, 2003) — a prediction that has been subjected to empirical tests (Giessner \& van Knippenberg, 2008; Giessner et al., 2009; Platow \& van Knippenberg, 2001; Platow et al., 2006; van Knippenberg \& van Knippenberg, 2005). An important element in group members' willingness to follow a leader and be open to the leader's influence is the expectation that the leader acts with the group's best interest in mind — and is “doing it for 
us" (Haslam \& Platow, 2001). This expectation is positively impacted by leader group prototypicality; group norms, values, and interests are an integral part of the group prototype, and being perceived to be group prototypical is intertwined with the perception that the leader has these norms, values, and interests at heart. Group-serving behavior (e.g., self-sacrifice on behalf of the group; van Knippenberg \& van Knippenberg, 2005) also feeds into this expectation that past behavior will predict future behavior. Leaders are not expected to continuously prove their group-serving motivations, however. Once trust in leader groupservingness is established, further signals to that effect are less consequential. In effect, this means that leader group prototypicality and leader group-serving behavior substitute for each other's influence in that either one is sufficient to instill the trust in leader group-serving motivations that feeds into leadership effectiveness (Giessner \& van Knippenberg, 2008).

Although these moderation effects have been summarized in narrative reviews (e.g., Hogg et al., 2012), they have not been subjected to a meta-analytic examination. This is important because while some studies have found support for the moderating role of follower group identification (e.g., van Dijke \& De Cremer, 2008) and leader group-serving behavior (e.g., van Knippenberg \& van Knippenberg, 2005) others have found that follower group identification (e.g., Hogg, Hains, \& Mason, 1998: Study 1) and leader group-oriented behavior (Platow et al., 2006: Study 1) do not moderate the effect of leader group prototypicality. To provide a more comprehensive picture of the state of the science, we therefore seek to establish meta-analytically whether these are robust effects that hold across the available body of evidence. Thus, in line with early theorizing, we hypothesize:

H5. Leader group prototypicality will be more strongly associated with leadership outcomes to the extent that followers identify strongly with the group.

H6. Leader group prototypicality will be more weakly associated with leadership outcomes to the extent that leaders display high levels of group-oriented behavior. 


\section{Overview of Present Research}

In the present research, we advance the social identity theory of leadership by subjecting the four novel hypotheses outlined in the previous sections to a meta-analytic test. In addition, the available evidence also allows us to rigorously explore the impact of two moderators examined in primary research. Specifically, we sought to examine whether leaders who are in-group prototypical are effective not only for subjective evaluations of perceived leadership (as shown in previous work; Barreto \& Hogg, 2017), but also for behavioral outcomes. In the study of leadership, behavioral outcomes (e.g., performance, creativity, citizenship) are of greater interest because they are not only more closely aligned with the understanding of leadership effectiveness in terms of the pursuit of group goals (Kaiser, Hogan, \& Craig, 2008) but also influenced to a lesser extent by perceptual biases and common method variance (van Knippenberg, 2012). In this regard, while there are no direct tests from primary leader group prototypicality research, it is plausible to expect that subjective evaluations of leadership will be more strongly impacted by perceptions of leader group prototypicality than behavioral outcomes. Importantly, though, the effect of leader group prototypicality should also be apparent for behavioral outcomes.

Finally, we will take advantage of the unique benefits afforded by meta-analyses to assess the presence of various indicators of publication bias (e.g., due to file-drawer and small study effects, Kepes et al., 2012) to obtain an indication of the cumulative reliability of the present literature (Cumming, 2014; Cumming \& Calin-Jageman, 2017; Schmidt \& Oh, 2016).

\section{Methods}

Following best-practice recommendations, in conducting and reporting the present research, we followed the American Psychological Association's Meta-Analysis Reporting Standards (MARS; Appelbaum et al., 2018) and the Preferred Reporting Items for Systematic 
reviews and Meta-Analyses (PRISMA; Moher, Liberati, Tetzlaff, Altman, \& Prisma Group, 2009).

\section{Study Search Procedure}

A flow diagram displaying an overview of the literature search procedure is presented in Figure 1. Three trained independent coders with a degree in psychology conducted a literature search for relevant studies in Web of Science, PsycINFO, and Google Scholar (so that each data base was searched by two different coders) using the following keywords: leader group prototypicality OR leader prototypicality OR prototypical leader OR leader embodiment OR leader representativeness OR supervisor organizational embodiment OR leader organizational embodiment $O R$ social identity and leadership. To be included, all articles were required to have been conducted and reported by January 2020. Overall, this search identified a total of 6,008 articles. In the first phase, 356 duplicate articles were removed, and the remaining were screened for potential relevance on the basis of their title and abstract, and in cases in which the title and abstract did not allow determination of the relevance of the article, the full text was inspected. The phase identified 278 unique articles for further full-text review. In the second phase, we conducted a full-text search of these remaining articles and excluded irrelevant articles based on our inclusion and exclusion criteria (as detailed below), resulting in a total sample of 59 unique articles. Furthermore, to ensure the completeness of this procedure, we also searched all articles that cited influential reviews by Hogg (2001), Haslam, Reicher, and Platow (2011), Hogg, van Knippenberg, and Rast (2012), and van Knippenberg (2011). At the time of review, 2,234 articles cited Hogg (2001), 1,198 articles cited Haslam et al. (2011), 273 cited Hogg et al. (2012), and 257 articles cited van Knippenberg (2011). Reviewing these citations resulted in 11 additional articles.

Finally, to address publication bias and obtain a more accurate estimation of the effect 
size based on all existing data, we sought to obtain and include unpublished data (including from dissertations, conference presentations, book chapters, and unpublished manuscripts). With this in mind, we sent out calls for data via leading associations in social and organizational psychology and management including the Society for Personality and Social Psychology, the Academy of Management's Organizational Behavior Division, the European Association of Social Psychology, the European Association of Work and Organizational Psychology, the German Psychological Society, and the Society for Australasian Social Psychology. In addition, we contacted the authors of articles reporting primary data that our literature search identified to seek additional unpublished data/reports they may have. These calls allowed us to obtain an additional 11 reports. Altogether, this search strategy resulted in a final sample of 128 independent samples (251 effect sizes, $N=32,834)$. The sample included data from published journal articles $(k=90)$, dissertations/theses $(k=25)$, unpublished manuscripts $(k=7)$, unpublished data $(k=3)$, and conference presentations $(k=$ 3). All references to studies reporting primary data that have contributed to the analysis are marked with asterisks and an overview of the included samples is presented in the Supplemental Materials (see Table S1).

\section{Inclusion Criteria}

Data were included on the basis of the following inclusion and exclusion criteria. We included data concerning quantitative assessments of the relationship between leader group prototypicality and at least one leadership outcome. We included data based on studies employing experimental, cross-sectional, and longitudinal methods. Data based on studies employing qualitative methods as well as theory and review articles that did not report primary data were excluded. Data were included if they were gathered by means of an experimental manipulation or a quantitative measure of a leader's prototypicality of a collective group (i.e., manipulating or assessing the extent to which the leader is prototypical 
of a group, team, or organization). Data were excluded if they related to (a) leaders' prototypicality of other entities including prototypicality of leaders in general (rather than the specific group that they were leading; e.g., van Quaquebeke, Graf, \& Eckloff, 2014), (b) ingroup versus outgroup leaders (e.g., Duck \& Fielding, 1999), or (c) a group's prototypicality of a superordinate group (e.g., Thomas, Amiot, Louis, \& Goddard, 2017).

Data were included if they related to the explicit assessment of at least one indicator of effective leadership (e.g., perceived leader effectiveness, trust in the leader, follower performance; see overview of variables and corresponding number of effect sizes in Table 3). Finally, to be included, studies had to be reported in English and provide necessary statistical information for analysis (this led to eight papers being excluded: one in Arabic, one in Korean, two in Chinese, one in Lithuanian, and three in Spanish). In cases in which data were missing or coding was hindered by ambiguous reports, we contacted the author(s) of the paper via email to request missing data (we sent out two additional reminders at an interval of one week if the author(s) had not responded within two weeks). We were unable to contact four authors due to the absence of valid contact details from the report and no available details online. Of the 16 authors who we contacted, 12 authors responded with missing data, three authors responded by informing us that they were not able to provide missing data, while one author did not respond. In cases in which we were not able to obtain missing data, we computed effect sizes from statistics provided in the paper where possible (in two cases there was insufficient information reported and so the report was excluded).

\section{Study Coding Procedure}

For each study, we coded several variables as described in more detail below including author names, year of publication, country the sample resided, sample size, publication status, leader outcome, average vs. ideal member conceptualization, prototype strength: short-lived vs. enduring group, implicit vs. explicit intergroup context, formal vs. 
non-formal leader position, leader outcome index, leader group prototypicality scale, effect size, and study methodology. In the case of two moderators (the two most often examined moderators) — followers' social identification with the group and leaders' group-serving behavior - several studies reported explicit tests of the moderation of the leader group prototypicality-effectiveness relationship by respondents' social identification and by leaders' group-serving behavior. For these two factors, we thus coded the effect size of the interactions between leader group prototypicality and followers' social identification and between leader group prototypicality and leaders' group-serving behavior to meta-analyze the effect size of the moderation test.

Two independent coders, who both had a degree in psychology, received training concerning the variables of interest before coding all variables independently. Agreement between coders was high $(95.96 \%$, Cohen's Kappa $=0.919$; Cohen, 1960). Discrepancies between coders were resolved in discussion with the first author.

Leader group prototypicality scale. We coded effect sizes based on the inventory used in cross-sectional and longitudinal studies to assess leader group prototypicality. Common scales to assess leader group prototypicality are presented in Table 1 . The most commonly used scales were the leader group prototypicality scale developed by Platow and van Knippenberg (2001; 49 effect sizes), the leader prototypicality scale developed by van Knippenberg and van Knippenberg (2005; 36 effect sizes, which extends Platow and van Knippenberg's scale), the leader identity prototypicality subscale of Steffens et al.'s (2014) Identity Leadership Inventory (33 effect sizes), and Eisenberger et al.'s (2010) supervisor organizational embodiment scale (25 effect sizes). Because van Knippenberg and van Knippenberg's (2005) scale is based on Platow and van Knippenberg's (2001) scale, some studies referenced both scales and in these cases we coded the effect size as being based on Platow and van Knippenberg (2001). The remaining 29 effect sizes based on residual other 
scales created specifically for the study in question were coded as 'other'.

Leader outcome. We grouped measures in terms of the nature of the outcomes they assessed. An overview of the outcomes is presented in Table 3. To ensure comparability of effect sizes, in cases where a leader outcome denoted reduced effectiveness (e.g., counterproductive work behaviors), we reverse-coded the sign of the effect size so that a positive effect size indicated higher effectiveness.

Evaluative vs. behavioral index. We coded outcomes as evaluative (subjective leadership evaluations, such as perceived effectiveness or charisma) or behavioral outcomes (indicators such as in-role and extra-role performance).

Average vs. ideal group member. We coded the conceptualization and operationalization of prototypicality as referring to the leader being the typical, average member of the group or the ideal member of the group. For correlational studies, operationalizations were coded as typical when all the scale items assessing the leader's prototypicality referred exclusively to the leader being 'similar', 'typical', or 'representative' of the group (or used other similar words). Operationalizations were coded as ideal when the scale items assessing the leader's prototypicality included at least one reference to the leader 'exemplifying', 'epitomizing', or 'being a model of' what it means to be an ideal member of the group (or used other similar words). For experimental studies, we similarly coded the descriptions of the leader in the experimental manipulations. It is noteworthy that none of the manipulations included references to the leader as being an ideal-type group member and all exclusively described the leader as the average group member.

Implicit vs. explicit intergroup context. We coded whether experimental studies manipulated prototypicality in an implicit intergroup context (no explicit references to the presence of other (out-)groups) or explicit intergroup context (referring explicitly to other (out-)groups — for example, by providing information about differences between the ingroup 
and another (out-)group). It is noteworthy that none of the correlational studies included explicit references to any (out-)groups and so the analysis focussed exclusively on experimental studies.

Prototype strength. As noted, prototype strength was indexed by group longevity, for which we coded whether the group was a short-lived group (i.e., novel ad hoc group created at the commencement of the study and that did not exist beyond the completion of the study such as an in-person lab group, simulated work team, or short-lived group in the field) or an enduring group (i.e., a natural group that already existed prior to the study such as a work unit, political party, or student group).

Prototypicality of member in formal vs. non-formal leadership position. We coded whether the target person occupied a formal leadership role (e.g., a supervisor, political leader, CEO) or held a non-formal leadership position (e.g., as a group member whose leadership was being evaluated, a candidate for a position as group leader).

Effect size. We coded Pearson's $r$ between leader group prototypicality and outcome for cross-sectional and longitudinal designs (where $r$ was averaged over time points). For other effect sizes such as Cohen's $d$, we converted the effect sizes into Pearson's $r$ prior to analysis (using the formulas provided by Borenstein, Hedges, Higgins, \& Rothstein, 2009, Rosenthal, 1991; Peterson \& Brown, 2005).

\section{Effect size for moderation by followers' social identification with the group.}

Because a large number of studies $(k=15 ; 25$ effect sizes; $N=7,798)$ reported data concerning direct tests of the moderation of the leader group prototypicality-outcome relationship by follower identification with the group, we coded the effect size for the interaction effect with a view to meta-analyzing this interaction effect statistic. We coded means and standard deviations for all cells before computing an effect size analogous to Cohen's $d$ (using the formula provided by Westfall, 2015). Specifically, for experimental 
studies, we first calculated the simple main effect (in terms of standardized mean difference) of leader group prototypicality within each level of the moderator (i.e., within the conditions of low leader group-serving behavior and then within the conditions of high low leader group-serving behavior). We then subtracted the standardized mean difference in the low group-serving condition from the standardized mean difference in the high group-serving condition, to obtain an estimation of the effect size of the interaction effect.

For studies in which the means and standard deviations were not available, we used $F$-test statistics to calculate $r$ (using the formula described above by Rosenthal, 1991, p. 19). For studies that tested the moderation via linear regressions, we converted the standardized regression coefficient corresponding to each interaction to $r$ (using the formula provided by Peterson \& Brown, 2005). To ensure comparability of effect sizes, only standardized regression coefficients were used (Peterson \& Brown, 2005; Schielzeth, 2010) and from models that only contained the main effects and interaction effect sizes and not any other (e.g., control) variables as these might influence the effect size estimate (Peterson \& Brown, 2005). All effect sizes were coded such that the effect of leader prototypicality on positive leader outcomes increases to the extent that social identification increases.

Effect size for moderation by leader group-serving behavior. A substantial number of samples $(k=9 ; 15$ effect sizes; $N=1,729)$ provided direct tests of the moderation of the leader group prototypicality-outcome relationship by leader group-serving behavior. We coded the effect size for the moderation by leader group-serving behavior in the same manner as for moderation by followers' social identification. All effect sizes were coded such that the effect of leader prototypicality on positive leader outcomes decreases to the extent that the leader demonstrates group-serving behavior.

Study methodology. We coded whether studies used survey designs (assessing leader group prototypicality; 172 effect sizes) or experimental designs (manipulating leader group 
prototypicality; 79 effect sizes). In longitudinal study designs, zero-order correlations were averaged over multiple time points. Studies that measured prototypicality but manipulated other variables were coded as correlational designs for the purpose of the present analysis.

Sample size. We coded the sample size that an effect size estimation was based on.

Publication status. We coded whether the effect size was published or unpublished.

\section{Analytic Procedure}

The majority of primary research reported correlations, and so we used meanweighted $r$ as effect size of choice. Given that our data included a substantial number of studies reporting mean differences, we followed suggestions from Borenstein and colleagues (2009) to combine effect sizes from different study designs by converting to a common effect size. To perform the meta-analysis we followed procedures developed by Borenstein, Hedges and colleagues (Borenstein et al., 2009; Hedges \& Olkin, 1985; Hedges \& Vevea, 1998). All analyses were conducted using R open-source software (version 3.6.1; R Core Team, 2016) within the RStudio environment (version 1.1.463; RStudio Team, 2016) using the packages Metafor (Viechtbauer, 2010), plyr (Wickham, 2011) and QuantPsyc (Fletcher, 2012), following guidelines provided by Viechtbauer (2016) and Assink and Wibbelink (2016).

A large portion (53.90\%) of studies in our dataset reported multiple effect sizes, thereby violating assumptions of independence of effect sizes required for traditional metaanalytic approaches. Dependency among effect sizes has commonly been resolved by choosing one effect size from each study or by averaging across effect sizes (e.g., Borenstein et al., 2009; Lipsey \& Wilson, 2001). However, this results in overestimation of the standard errors leading to an increase in Type-2 error (i.e., failure to reject a false null hypothesis; for a review and demonstration see Moeyaert et al., 2017), and a loss of information about potential meaningful effect size variation as a function of the outcome (Van den Noortgate, López-López, Marín-Martínez, \& Sánchez-Meca, 2014). To account for non-independence of 
effect sizes, we therefore used a three-level meta-analytic model that explicitly models the effects of independent samples and of different effect size indices (for reviews see Moeyaert et al., 2017; Van den Noortgate et al., 2014; Van den Noortgate \& Onghena, 2003). This is the most appropriate and accurate estimation technique for the present data structure in which there are multiple outcomes and where different outcomes can be meaningfully clustered (around the dependent variables described above). The three-level model has the advantage that it splits the total variance into the sampling variance for each effect size (level 1), the within-study variance (level 2), and the between-study variance (level 3) and combines the regression equation at each level into a three-level meta-analytic regression equation (for a review see Moeyaert et al., 2017) — something which is not possible with alternative estimation techniques such as traditional aggregated (univariate) models or robust variance estimation (RVE; Hedges, Tipton, \& Johnson, 2010). All parameters estimation of the summary effect size and the moderators were estimated using the Restricted MaximumLikelihood Estimator (Viechtbauer, 2005). In industrial and organizational psychology (not so much in other areas), researchers have sometimes used the Hunter and Schmidt method which was designed to correct for measurement in psychometric testing and aims to estimate corrected correlation coefficients (which tend to be larger than the raw uncorrected correlations coefficients) after taking into consideration measurement error (counteracting attenuation due to measurement bias). This method is useful for meta-analyses in industrial and organizational psychology that are often based exclusively on correlational (or longitudinal) studies. This method is not used in other fields (e.g., cognitive or social psychology) that tend to use experimental studies because there is no measurement error in a psychometric sense in experiments where the independent variable is manipulated (even though in experiments as in other methods, there can be various other potential sources of error). A large proportion of the present studies are experimental studies and so for the sake 
of comparability of effect sizes, the present analyses refrains from conducting additional analyses using this approach.

To assess moderators, we conducted a multilevel mixed-effects model with variance pooled across the groups (in the Metafor package this is akin to subgroup analysis with pooled variance as in Borenstein et al., 2009; Viechtbauer 2010; Viechtbauer 2016). As in the summary model, parameters were estimated with the Restricted Maximum-Likelihood Estimator (Viechtbauer, 2005) and one-sided log-likelihood-ratio tests were used to examine whether the variance (level 2 and level 3) not accounted for by the moderator was significantly from zero.

We followed recommendations by Kepes et al. (2012) by inspecting publication bias using a number of techniques as reported below. Finally, we calculated a summary effect size for the moderating effect of (a) followers' social identification (b) leaders' group-serving behavior using a three-level random-effects model as in the summary effect model.

\section{Results}

\section{Summary Effect Analyses}

A three-level random-effect model across the studies (251 effect sizes, $k=128, N=$ 32,834 ) indicated that the mean-weighted relationship was positive, $r=.38,95 \%$ CIs [.34, $.43], t(250)=16.00$. A forest plot displaying the distribution of the effect sizes (and confidence intervals) across studies can be found in the Supplemental Materials online (Supplementary Figure S1). The overall heterogeneity in all effect sizes was larger than expected due to sampling error, $Q(250)=6351.39, p<.001$, and a substantial amount of the total variation was due to true differences both within-studies (Level 2: $I_{2}=34.26 \%$ ) and between-studies (Level 3: $I_{2}=61.85 \%$ ), rather than to sampling error (Level 1: 3.89\%). There was significant within-study variance, $\sigma_{\text {level } 2}^{2}=.032, \chi_{2}(1)=2155.33, p<.001$, and betweenstudy variance, $\sigma_{\text {level } 3}^{2}=.057, \chi_{2}(1)=59.73, p<.001$, indicating the likely presence of 
moderating variables - a possibility we explore further below. The $80 \%$ prediction interval (Raudenbush, 2009) indicates a probability of $80 \%$ that the true effect size of a new study is likely to fall somewhere within the range of .02 to .66 .

\section{Publication Bias Analyses}

We used several techniques to estimate publication bias. For the funnel plot asymmetry test and trim-and-fill method, the multilevel data were aggregated (averaged across effect sizes) as multilevel methods of these tests have not been developed. An integrative summary of the publication bias results are presented in Supplementary Table S2.

Funnel plot asymmetry test. Visual inspection of the funnel plot (as shown in Supplementary Figure S2) did not provide indication of asymmetry as a function of effect size and standard error. Furthermore, we used Egger and colleagues' (1997) regression test by including standard error as a moderating variable in the summary model. An intercept of the regression line that differs from zero indicates that the funnel plot is asymmetrical (Sterne \& Egger, 2005), and the regression test indicated that there was no evidence of asymmetry, $z$ $=-1.13, p=.257$. We further inspected potential asymmetry by means of the trim-and-fill method and analysis by sample size.

Trim-and-fill method. Duval and Tweedie's (2000) trim-and-fill method indicated some asymmetry in effect sizes to the right side of the mean due to potential underreporting of effect sizes above the point estimate. The direction is contrary to what one would expect if publication bias led to over-representation of large effect sizes. Adjustment for asymmetry by imputing 17 missing effect sizes produced an unbiased positive effect size that was slightly larger than the effect without such imputation: $r=.43[.39, .47], Z=17.35, p<.001$.

Analysis by publication status. Results indicated a significant positive relationship based on both published $(k=89)$ samples, $r=.36[.31, .41], t(249)=12.66$, and unpublished 
$(k=39)$ samples, $r=.43[.35, .50], t(249)=10.03, F(1,249)=1.81, p=.18$, providing little evidence that results were influenced by publication status.

Analysis by sample size. A meta-regression with sample size as the predictor of the effect size (Kühberger et al., 2014) provided no evidence that the effect size was predicted by sample size, $b=.0000[-.0000, .0001], t(249)=0.98, p=.33$. Furthermore, estimation of the summary effect size based only on half of the studies that have the largest samples $(k=64$, effect sizes $=124)$ yielded an effect size, $r=.43,[.37, .49], t(123)=12.43$, that has the same substantive implications as the effect size based on the total sample size.

\section{Hypothesis Tests}

Intercorrelations between variables are presented in Table 2. Results from moderation analyses are presented in Table 3.

Average vs. ideal group member. The focal relationship was positive in studies in which prototypicality referred exclusively to the leader being an average member of the group, $r=.35[.30, .39], t(249)=14.03$. The relationship was also positive and stronger in studies in which prototypicality was conceptualized by including references to the leader as being an ideal member of the group, $r=.55[.46, .63], t(249)=10.14$. The between-group variance was larger than expected due to sampling error, $F(1,249)=14.99, p<.001$, indicating that, as suggested by $\mathrm{H} 1$, the relationship is stronger when leaders' group prototypicality refers not just to the leader as a typical group member who is maximally similar to other members but also to him or her as an ideal group member who exemplifies what is special about the group. 1

1 We also ran an additional alternative moderation analysis based on alternative coding of ideal conceoptualizations of prototypicality (by coding the proportion of items in a scale that captured ideal notions of prototypicality). Results of this analysis are similar to the main analysis indicating that proportion of items assessing ideal notions moderated the effect size, $b=.51, S E=.14, t=3.55, p=.001$. 
Implicit vs explicit intergroup context. The focal relationship was positive both when leader group prototypicality was manipulated by referring only to communalities within the group (in implicit intergroup contexts), $r=.19[.12, .27], t(77)=5.02$, and when it also referred to differences from other groups (in explicit intergroup contexts), $r=.29[.18, .38]$, $t(77)=5.46$. There was thus no support for $\mathrm{H} 2$ in so far as between-group variance was not greater than would be expected due to sampling error, $F(1,77)=2.10, p=.15$.

Prototype strength: Short-lived vs. enduring groups. The focal relationship was positive in groups in short-lived groups, $r=.29[.22, .37], t(249)=7.34$, but it was stronger in enduring groups, $r=.43[.38, .48], t(249)=15.08$. The variance between the groups was greater than would be expected on the basis of sampling error, $F(1,249)=9.50, p=.002$. In line with $\mathrm{H} 3$, this indicates that the relationship is stronger for leaders of enduring groups.

Prototypicality of member in formal vs. non-formal leadership position. The relationship was positive for leaders in formal leadership roles, $r=.41[.37, .46], t(249)=$ 16.03, and for those in non-formal leadership roles, $r=.26[.16, .36], t(249)=4.82$. Supporting H4, the overall between-group variance was significantly greater than expected due to sampling error, $F(1,249)=7.81, p=.006$, indicating that the leader prototypicalityoutcome relationship is stronger for leaders in formal leadership roles, than for those occupying non-formal leadership roles.

Followers'social identification. A three-level meta-analysis of the interaction effect sizes across all samples that provided data for the direct tests of the interaction between leader group prototypicality and followers' social identification on leader outcomes indicated an overall robust effect of $r=.16[.11, .20], t(24)=6.61$. This shows that the relationship between leaders' group prototypicality and outcomes is stronger as followers' social identification with the group in question increases. To illustrate the strength of the interaction effect, given the summary effect of $r=.38$ and the present interaction effect of $r=.16$, at low 
levels of followers' social identification, the prototypicality-outcome relationship equals $r=$ .30 , and then increases to $r=.46$ at high levels of followers' social identification (denoting a $53 \%$ increase in the magnitude of the effect when followers identify strongly, rather than weakly, with the group).

The overall heterogeneity between effect sizes was greater than would be expected due to sampling error, $Q(24)=71.50, p<.001$, with the largest proportion of the variance due to sampling error (Level 1: $I_{2}=42.53 \%$ ), and the remaining proportions due to true differences between effect sizes (Level 2: $I_{2}=18.06 \%$ ) and true differences between studies (Level 3: $I_{2}=39.40 \%$ ). In the model estimating the effect of follower social identification, the residual between-study variance was not significant, $\sigma_{\text {level } 3}^{2}=.003, \chi_{2}(1)=1.23, p=.268$. The $80 \%$ prediction interval suggests that the effect size for the interaction in a new study is likely to fall within the range between .06 to .25 .

Leader group-serving behavior. A three-level meta-analysis of the interaction effect sizes across all samples that provided data for the direct tests of the interaction between leader group prototypicality and leader group-serving behavior on leader outcomes indicated a robust effect of $r=-.14[-.18,-.09], t(14)=6.45$, demonstrating that the impact of leaders' prototypicality on leader outcomes is weaker to the extent that leaders show behavior that advances group interests. Given a summary effect size of $r=.38$ and the present interaction effect size of $r=-.14$, this means that magnitude of the relationship between leader prototypicality and leader outcomes equals $r=.45$ when the leader displays little groupserving behavior but then decreases to $r=.31$ when the leader shows elevated group-serving behavior (denoting a 30\% drop in the magnitude of the effect as leaders act to advance group interests).

The overall heterogeneity was not greater than expected due to sampling error, $Q(14)$ $=13.17, p=.513$, with the largest portion of variance due to sampling error (Level 1: $I_{2}=$ 
$89.21 \%$ ), and smaller portions due to differences between effect sizes (Level 2: $I_{2}=7.46 \%$ ) and differences between studies (Level 3: $I_{2}=10.79 \%$ ). The residual between-study variance was not significant, $\sigma_{\text {level } 3}^{2}<.001, \chi_{2}(1)=0.18, p=.671$. The $80 \%$ prediction interval suggests that the effect size for the interaction in a new study is likely to fall within the range between -.18 to -.09 .

Evaluative vs. behavioral index. Results indicated that the relationship varied as a function of evaluative vs. behavioral indicators, $F(1,249)=37.69, p<.001$, a finding that was anticipated and is not surprising. The important finding here is that the relationship was positive not only for evaluative outcomes, $r=.41[.37, .45], t(249)=17.62$, but also for behavioral outcomes, $r=.19[.11, .27], t(249)=4.68 .2$

\section{Moderation by Method Factors}

Leader group prototypicality scale. The focal relationship was positive across all measurement scales: Platow and van Knippenberg's (2005) scale, $r=.51[.43, .58], t(167)=$ 11.08, van Knippenberg and van Knippenberg's (2005) scale $r=.45[.34, .54], t(167)=7.70$, Steffens et al.'s (2014) scale, $r=.50[.39, .60], t(167)=7.48$, Eisenberger et al.'s (2010) scale, $r=.27[.12, .41], t(167)=3.43$, and other scales, $r=.44[.32, .56], t(167)=6.24$. The between-group variance was not statistically significantly greater than expected due to sampling error, $F(4,167)=2.41, p=.051$.

Study methodology. The relationship was positive in studies using experimental designs, $r=.23[.16, .30], t(249)=6.00$, and in those using correlational/longitudinal designs, $r=.46[.41, .50], t(249)=17.35$. The between-group variance was significantly greater than expected due to sampling error, $F(1,249)=28.30, p<.001$, indicating that the relationship

2 We conducted additional analyses to examine whether there was evidence that the effect of the conceptualization of prototypicality (average vs. ideal member) differed for evaluative and behavioural indices. Results revealed no evidence of an interaction between the conceptualization of prototypicality and outcome index, $b=.09, S E=.09, t=1.00, p=.260$. 
was stronger in studies that used survey designs rather than experimental designs. This makes sense because the majority of studies of short-lived groups are experimental studies (but not all, and there are experimental studies drawing on groups with higher longevity), and in line with our predictions for the role of prototype strength as well as group identification, there should be a natural correlation favoring, on average, stronger effects in the field. The key thing to highlight here, we believe, is that effect of leader group prototypicality also holds up in experimental tests that establish causality in this relationship. In addition, this is useful to know as this can help inform design of future studies in terms of sample sizes. For instance, in order to guarantee $90 \%$ statistical power, one would need a sample size of $N=45$ for a correlational study to detect a significant effect of $r=.46(d=1.04)$, and $N=178$ for an experimental study to detect a significant effect of $r=.24(d=0.49)$.

\section{Discussion}

Through meta-analysis we sought to advance the social identity theory of leadership in several ways. First and foremost, we tested novel hypotheses that clarify attributes of the theory's core concept of leader group prototypicality and its relationship with leadership outcomes. In addition, we provided a meta-analytic test of two core moderators (follower group identification and leader group-serving behavior) across the entire suite of primary studies that have examined this relationship. Furthermore, we examined the extent to which the link between leader group prototypicality and leader outcomes holds not only across evaluative follower responses but also for behavioral outcomes. Finally, in light of scholars' increasing calls for estimations of replicability of research findings in science more generally including management (Aguinis, Cascia, \& Ramani, 2017; Bettis et al., 2016; Kepes et al., 2012), we provided extensive tests of publication bias to interrogate the robustness of the evidence. In the following, we elaborate on these issues. 


\section{Theoretical Implications}

Leader group prototypicality is the core concept in the social identity theory of leadership, and our analysis advances theory by specifying four key insights related to the nature and impact of this variable. First, we established that the relationship between leader group prototypicality and outcomes is stronger when prototypicality is conceptualized in aspirational terms of the ideal-type for the group rather than simply in descriptive terms with reference to a group average. This is consistent with the notion that it is the aspirational element of group prototypicality — who we would be ideally — that renders group prototypicality a basis for leaders' social influence. This finding is important because it allows us to link leader group prototypicality more explicitly to what is arguably at the core of leadership — motivating and mobilizing group members to pursue objectives that are central to the group (e.g., the team, unit, or organization). Teams and organizations may pursue many objectives, and some are more central to the team or organization than others. Mission, vision, and strategy arguably are most fundamental to organizational goal pursuit (Stam, Lord, van Knippenberg, \& Wisse, 2014), and these are objectives closely tied to the organization's aspirations and to the organization's prototype (van Knippenberg, 2020). Arguably, then, here in particular the aspirational element of leader group prototypicality would be important, because this gives leaders credibility in advocating the pursuit of these group-prototypical objectives.

Second, leader group prototypicality is more strongly related to leadership outcomes with stronger (vs. weaker) prototypes, as indexed by group longevity. Whereas no proxy variable can be equated with the concept, group longevity can be seen as foundational to prototype strength (Oakes et al., 1994). With the caveat, then, that our analysis does not demonstrate this directly, we would suggest that leader group prototypicality has stronger effects in more enduring groups because of more firmly established (stronger) mental 
representations of group prototypes in such groups (as compared with shorter-lived groups). This finding is important in understanding differences between groups in terms of how strong a basis they provide for social identity-based influence. That said, primary research is needed to provide more direct analyses of prototype strength to further clarify its contribution to leader effectiveness. Such follow-up research would also be valuable to develop two implications of the notion that leader group prototypicality has more pronounced effects for stronger group prototypes. First, it seems plausible that there can be variations in prototype strength between members of the same group. Some group members may hold stronger group prototypes (i.e., better developed mental representations) than others as a function of, for example, their own group tenure (i.e., their status as long-standing members vs. newcomers). Groups may also vary over time in prototype strength, not only in terms of the current comparison in terms of group tenure but also in terms of changes to the group that may at least temporarily render the group identity less well-defined (e.g., in times of organizational change; Venus, Stam, \& van Knippenberg, 2019).

The notion of prototype strength as a moderating influence should apply to a broader range of differences within and between groups than just differences captured by group longevity, and is a research avenue worth exploring in its own right. In this regard, the notion of prototype strength is also relevant to Reicher and Hopkins' (2001) observation that leaders are "entrepreneurs of identity" who play an active role in shaping people's understanding of group identity (see also Haslam et al., 2011; Reicher et al., 2005; Steffens et al., 2014). Combining the notion of prototype strength with these insights in leader agency in group members' social identity construction, we also propose that it is partly by building the strength of the group prototype (i.e., members' mental representation of group identity) that group prototypical leaders are able to secure a basis for their identity-based influence.

Third, our understanding of leader group prototypicality is also enriched by the 
finding that effects are more pronounced for leaders in formal than in non-formal leadership positions. In particular, this shows that there is a distinct leader role component to leader group prototypicality effects and that these effects do not simply revolve around the group prototypicality of any group member who happens to be fulfilling a leadership role. This suggests that there is further scope for theory to clarify and examine further what it is that makes prototypicality powerful for the discharge of formal leader roles. One answer may be that this is where leadership matters most and hence where followers are most sensitive to leadership prototypicality. Support for this hypothesis also begs the question of whether perceived authority (or legitimacy), responsibility for the group, or the task of representing the group (e.g., for elected officials) are active ingredients here, and whether the importance of prototypicality for formal leaders varies as a function of these factors. Again, these are important issues to address in primary research in the interests of further developing theory.

We found no support for the prediction that leader group prototypicality has stronger effects when it was explicitly operationalized in terms of intergroup comparison. Clearly in the papers we reviewed, some primary findings indicated an effect of the salience of the intergroup context, while others did not. Given this variability in primary findings, we recommend future analyses seek to deconstruct this variable further. In particular, it may be fruitful to understand more fully the nature of the intergroup context. For example, in conflictual intergroup contexts, the salience of an outgroup may enhance a group prototypicality effect, but not have the same effect in more pallid intergroup contexts where the outgroup is irrelevant to how group members define themselves. Alternatively, it may be noted that even when a measure or experimental induction does not explicitly invoke the intergroup context, such a context may be implied. Indeed, there are strong grounds for thinking that the perception of being a group inherently implies the existence of other groups (Turner et al., 1987). Accordingly, responses to measures or experimental inductions may be 
infused by the perceived intergroup context even when such context is not made explicit.

Together, then, the above findings provide robust evidence for core propositions of the social identity theory of leadership. Specifically, they show that the main effect of leader group prototypicality does not only hold for subjective leadership evaluations (Barreto \& Hogg, 2017), but also for the behavioral outcomes that are seen as the core issue in leadership effectiveness (Burns, 1978; House et al., 2001; Kaiser et al., 2008). In this regard, results show that leader group prototypicality exerts no small influence on leadership outcomes. Regarding the magnitude of the summary effect, it is worth noting that the overall effect size of $r=.39$ that we obtain from our analysis is substantially larger than the average effect size of $r=.29$ found in a review of 69 leadership meta-analyses summarizing more than 2000 studies on a range of leadership variables and outcomes (Paterson, Harms, Steel, \& Credé, 2016). Furthermore, results also consolidate support for two moderators that have been key propositions in the theory: follower social identification and leader group-serving behavior (e.g., Hogg et al., 2012). Finally, a sign of the robustness of the evidence is that the research that has examined the social identity theory of leadership is characterized by a large proportion of experimental studies that can shed light on causality — something which is not the case for the general evidence base in leadership research (Avolio Reichard, Hannah, Walumbwa, \& Chan, 2009; Podsakoff \& Podsakoff, 2019).

Beyond this, the meta-analytic approach we have taken also allows us to assess the influence of various methodological factors and publication bias. This is important because a cumulative and replicable body of evidence is essential for any field of science and is a necessary foundation for scientific advance (Schmidt \& Oh, 2016). In the present case, it is noteworthy that we addressed issues of publication bias by gathering unpublished data and subjecting the literature to analysis using a range of advanced techniques. These provided little indication that research evidence was adversely affected by publication bias. 
In sum, then, the present evidence underscores the value of studying leadership as a process that is shaped by shared social identity and leader group prototypicality. At the same time, it is notable that a comprehensive review of leadership research since 2000 by Dinh and colleagues (2014) showed that the social identity analysis of leadership informed only a small minority (4\%) of studies in this area. In view of the evidence that leader group prototypicality has stronger than average effects on leadership outcomes (cf. Paterson et al., 2016) and the fact that the core propositions of the theory are all well-supported, it would seem that there is a case for leadership research to embrace the social identity theory of leadership and explore ways to integrate the theory with other well-supported perspectives on leadership (Haslam et al., 2011; van Knippenberg \& Hogg, 2003).

\section{Implications for Practice}

To some extent, we need to be careful not to be too bold in identifying implications for practice, given that the tradition in leadership selection and development - the obvious foci for practical implications of leadership research — is more focused on leader traits and behaviors than on follower responses to those leaders. However, as we noted in the previous section, the effect size for leader group prototypicality suggests that prototypicality is far from a trivial determinant of leader outcomes. Indeed, this effect appears to be stronger than that associated with leader personality or behavioral aspects of leadership identified in other meta-analyses (e.g., Judge, Bono, Ilies, \& Gerhardt, 2002). Moreover, the solid support for the social identity theory of leadership would suggest that organizations might seek to build leadership effectiveness by selecting and developing group prototypical leaders. However, the social identity analysis of leadership also cautions those members of organizations doing the selecting and doing the developing. This is because the analysis recognizes that the normative content of "who we are" is actively debated among group members. Empirically, we know this from the in-group self-stereotype literature (Haslam et al., 1998), from the 
schism literature (Sani, 2008), from the in-group projection literature (Wenzel, Mummendey, \& Waldzus, 2008), and from the normative conflict literature (Crane \& Platow, 2010). What this means, is that those who appoint (or anoint) themselves to select and develop may have views about what is and is not prototypical of the salient group that is at odds with the views of prospective followers, which requires negogiation at best and risks failure at worst.

In part, then, this selection would entail selecting on the basis of a match with organizational identity and broader associated norms, values, and ambitions in ways that are recognized as procedurally legitimate. In part it would also involve recognizing that leaders need to be entrepreneurs of identity who actively shape the perception of their own and others' group prototypicality and the group prototypicality of the objectives they advocate (in ways suggested by Reicher \& Hopkins, 2001; see also Haslam et al., 2011; Steffens et al. 2014; van Dick et al., 2018). As noted above, this would also include shaping an understanding of group identity to build stronger prototypes. At the same time, the actions that leaders might take to that effect — the focus of leadership development efforts — are as yet poorly understood (for an exception, see Haslam et al., 2017). The accumulated evidence suggests, however, that it may be worth investing in further developing this understanding for practical application.

\section{Limitations and Directions for Future Research}

Meta-analyses have clear strengths in systematically synthesizing a body of evidence. At the same time, there are limitations to meta-analysis that we should be mindful of and that also apply to the current analysis. An obvious limitation is that meta-analyses are limited by the available evidence. This means that some relationships can only be studied by inference (e.g., as seen in our attempt to assess the impact of prototype strength by examining the effects of group longevity, which we could encourage future work to follow up with explicit measures and manipulations), and also that some relationships for which theory and evidence 
exist cannot be studied due to the limited number of effect sizes available for meta-analytic integration (e.g., as with research identifying motives that render followers more sensitive to leader group prototypicality; Pierro, Cicero, Bonaiuto, van Knippenberg, \& Kruglanski, 2005). As a result, meta-analysis has to be seen as complementing primary research and conceptual reviews, and a full evaluation of the social identity theory of leadership necessarily takes all three into account.

Meta-analytic tests of new theory also do not render future tests in primary research superfluous. Hypothesis tests based on coding of cross-study differences do not constitute causal evidence and may capture unmeasured variations between studies that covary with the coded variables. There is currently no study directly measuring and testing the effects of the four novel moderators of the relationship between leader group prototypicality and leader outcomes. The present evidence for these effects is strong in the sense that it is based on the quantitative integration of a large number of studies, but it is not based on direct, withinstudy assessment of these variables. Accordingly, future research to replicate and extend the current findings through within-study assessments of these effects would clearly be valuable.

Below, a number of key question limitations that future work should overcome to further our understanding in this field. First, we would note that many conceptualizations and operationalizations of prototypicality captured a mixture of average vs. ideal group prototypes. In this regard, there would be value in extending the analysis of the present relationships not only by distinguishing more clearly between these (and providing clear matching conceptualizations and operationalizations) but also by examining whether these have differential impact on different types of outcomes and given particular tasks.

Furthermore, it will also be interesting to examine a range of additional questions including how follower responses to different group prototypes are influenced by (a) the size of the discrepancy between current and ideal collective self as well as (b) variations in identity 
definitions (e.g., the degree to which a group is defined by ideal vs. average elements). Second, speaking to the idea of prototype strength, our examination of this idea was limited by the nature of the data. This would be important to interrogate further both conceptually and empirically, and to extend by examining a range of additional questions such as how follower responses to leader group prototypicality are influenced by the degree to which perceptions are shared among group members.

It would also be interesting in future research efforts to expand upon the present analysis by exploring whether, when and how intergroup contexts affect the impact of leader group prototypicality. For example, future work might examine how the impact of leader group prototypicality is affected by additional factors that influence the salience of intergroup contexts (e.g., specific events or contexts) as well as the nature of the relationship between the ingroup and other relevant outgroups (e.g., conflict in values and goals). Regardless of the specific questions that seem most pressing in future work, at a meta-research level, there would also be particular value in experimental work that can disentangle these effects while also establishing causality.

\section{Conclusion}

In this paper we sought to advance the social identity theory of leadership using a meta-analytic approach to explore novel questions about the nature and impact of leader group prototypicality. Results shed new light on several key characteristics of leader group prototypicality. Across published and unpublished data, results both confirm the effects of classic moderating factors that have previously received attention in primary research and clarify the impact of various methodological factors and publication bias. Overall, results identify an effect of leader group prototypicality that is moderate-to-large in magnitude and larger than typically found in other meta-analyses of leadership research. Beyond this, though, it also provides important insight into what exactly leader group prototypicality is 
and what makes it an important basis for leaders' effectiveness. And at the same time that these results consolidate findings of a very large (but often overlooked) body of research, they also point to important avenues for future research efforts. 


\section{References}

*Aicher, T. J., \& Cunningham, G. B. (2011). Organizational culture and leader sex impacts leader prototypicality and effectiveness. International Journal of Sport Management, 12, 344-360.

Aguinis, H., Cascio, W. F., \& Ramani, R. S. (2017). Science's reproducibility and replicability crisis: International business is not immune. Journal of International Business Studies, 48, 653-663.

*Alzoman, M. (2012). Effective leadership of a culturally diverse workforce in Saudi Arabia Basic Industries Corporation (SABIC). [Doctoral dissertation]. University of Portsmouth Research Portal.

Appelbaum, M., Cooper, H., Kline, R. B., Mayo-Wilson, E., Nezu, A. M., \& Rao, S. M. (2018). Journal article reporting standards for quantitative research in psychology: The APA Publications and Communications Board task force report. American Psychologist, 73, 3-25.

Ashforth, B. E., \& Mael, F. (1989). Social identity theory and the organization. Academy of Management Review, 14, 20-39.

Ashforth, B. E., Harrison, S. H., \& Corley, K. G. (2008). Identification in organizations: An examination of four fundamental questions. Journal of Management, 34, 325-374.

Assink, M., \& Wibbelink, C. J. M. (2016). Fitting three-level meta-analytic models in R: A step by step tutorial. Quantitative Methods for Psychology, 12, 154-174.

Avolio, B. J., Reichard, R. J., Hannah, S. T., Walumbwa, F. O., \& Chan, A. (2009). A metaanalytic review of leadership impact research: Experimental and quasi-experimental studies. Leadership Quarterly, 20, 764-784.

Banks, G. C., Kepes, S., \& McDaniel, M. A. (2012). Publication bias: A call for improved meta-analytic practice in the organizational sciences. International Journal of Selection and Assessment, 20, 182-196.

Barreto, N. B., \& Hogg, M. A. (2017). Evaluation of and support for group prototypical leaders: A meta-analysis of twenty years of empirical research. Social Influence, 12, 41-55.

*Barreto, N. B., \& Hogg, M. A. (2018). Influence and leadership in small groups: Impact of group prototypicality, social status, and task competence. Journal of Theoretical Social Psychology, 2, 26-33.

*Bertwistle, K. (2013). Managing workgroup values diversity: The underlying effect of collective team identity and the impact of identity leadership (Honours thesis). University of Queensland, Brisbane, Australia.

Bettis, R. A., Ethirai, S., Gambardella, A., Helfat, C., \& Mitchell, W. (2016). Creating repeatable cumulative knowledge in strategic management: A call for a broad and deep conversation among authors, referees, and editors. Strategic Management Journal, 37, 257-261.

Blader, S. L., \& Tyler, T. R. (2009). Testing and extending the group engagement model: linkages between social identity, procedural justice, economic outcomes, and extrarole behavior. Journal of Applied Psychology, 94, 445-464.

*Boezeman, E. J., \& Ellemers, N. (2014). Volunteer leadership: The role of pride and respect in organizational identification and leadership satisfaction. Leadership, 10, 160-173.

Borenstein, M., Hedges, L. V., Higgins, J., \& Rothstein, H. R. (2009). Introduction to metaanalysis. Hoboken, NJ: John Wiley.

Brewer, M. B. (1979). In-group bias in the minimal intergroup situation: A cognitivemotivational analysis. Psychological Bulletin, 86, 307-324.

Brewer, M. (1991). The social self: On being the same and different at the same time. Personality and Social Psychology Bulletin, 17, 475-482. 
Burns, J. M. (1978). Leadership. New York NY: Harper \& Row.

*Chang, J. W., Turan, N., \& Chow, R. M. (2015). A desire for deviance: The influence of leader normativeness and inter-group competition on group member support. Journal of Experimental Social Psychology, 56, 36-49.

Cialdini, R. B., Kallgren, C. A., \& Reno, R. R. (1991). A focus theory of normative conduct: A theoretical refinement and re-evaluation of the role of norms in human behavior. In L. Berkowitz (Ed.), Advances in experimental social psychology (Vol. 24, pp. 201234). San Diego, CA: Academic Press.

*Cicero, L., Bonaiuto, M., Pierro, A., \& van Knippenberg, D. (2008). Employees' work effort as a function of leader group prototypicality: The moderating role of team identification. European Review of Applied Psychology, 58, 117-124.

*Cicero, L., Pierro, A., \& van Knippenberg, D. (2007). Leader group prototypicality and job satisfaction: The moderating role of job stress and team identification. Group Dynamics: Theory, Research, and Practice, 11, 165-175.

*Cicero, L., Pierro, A., \& van Knippenberg, D. (2010). Leadership and uncertainty: How role ambiguity affects the relationship between leader group prototypicality and leadership effectiveness. British Journal of Management, 21, 411-421.

Cohen, J. (1960). A coefficient of agreement for nominal scales. Educational and Psychological Measurement, 20, 37-46

*Cookson, R. L. (2011(. The moderating effect of leader prototypicality on the relationship between LMX and follower attitudes [Master's thesis]. Retrieved from Georgia Tech Library. http://hdl.handle.net/1853/42709.

Crane, M. F., \& Platow, M. J. (2010). Deviance as in-group loyalty. British Journal of Social Psychology, 49, 827-847.

Cumming, G. (2014). The new statistics: Why and how. Psychological Science, 25, 7-29.

Cumming, G., \& Calin-Jageman, R. (2017). Introduction to the new statistics: estimation, open science, and beyond. New York: Routledge.

*Dai, Y. D., Hou, Y. H., Chen, K. Y., \& Zhuang, W. L. (2018). To help or not to help: antecedents of hotel employees' organizational citizenship behavior. International Journal of Contemporary Hospitality Management, 30, 1293-1313.

*Dawson, N. (2016). The post-crisis effects of leader prototypicality on public evaluations (Honours thesis). University of Queensland, Brisbane, Australia.

*De Cremer, D., van Dijke, M., \& Mayer, D. M. (2010). Cooperating when "you" and "I" are treated fairly: The moderating role of leader prototypicality. Journal of Applied Psychology, 95, 1121-1113.

*de Wolde, A., Groenendaal, J., Helsloot, I., \& Schmidt, A. J. (2014). An explorative study on the connection between ethical leadership, prototypicality and organizational misbehavior in a Dutch Fire Service. International Journal of Leadership Studies, 8, $18-43$.

Dinh, J. E., Lord, R. G., Gardner, W. L., Meuser, J. D., Liden, R. C., \& Hu, J. (2014). Leadership theory and research in the new millennium: Current theoretical trends and changing perspectives. Leadership Quarterly, 15, 36-62.

*Ditrich, L., Giesen, A., Kaltiainen, J., Hogg, M., \& Marques, J. (2017). Be innovative - but don't take it too far: Testing boundary conditions of the leeway-effect. Unpublished manuscript.

Doosje, B., Haslam, S. A., Spears, R., Oakes, P. J., \& Koomen, W. (1998). The effect of comparative context on central tendency and variability judgements and the evaluation of group characteristics. European Journal of Social Psychology, 28, 173184.

Duck, J. M., \& Fielding, K. S. (1999). Leaders and subgroups: One of us or one of 
them? Group Processes \& Intergroup Relations, 2, 203-230.

Duval, S., \& Tweedie, R. (2000). Trim and fill: A simple funnel-plot-based method of testing and adjusting for publication bias in meta-analysis. Biometrics, 56, 455-463.

Egger, M., Smith, G. D., Schneider, M., \& Minder, C. (1997). Bias in meta-analysis detected by a simple, graphical test. British Medical Journal, 315, 629-634.

*Eisenberger, R., Karagonlar, G., Stinglhamber, F., Neves, P., Becker, T. E., GonzalezMorales, M. G., \& Steiger-Mueller, M. (2010). Leader-member exchange and affective organizational commitment: The contribution of supervisor's organizational embodiment. Journal of Applied Psychology, 95, 1085-1103.

*Eisenberger, R., Shoss, M. K., Karagonlar, G., Gonzalez-Morales, M. G., Wickham, R. E., \& Buffardi, L. C. (2014). The supervisor POS-LMX-subordinate POS chain: Moderation by reciprocation wariness and supervisor's organizational embodiment. Journal of Organizational Behavior, 35, 635-656.

Ellemers, N., de Gilder, D., \& Haslam, S. A. (2004). Motivating individuals and groups at work: A social identity perspective on leadership and group performance. Academy of Management Review, 29, 459-478.

Elsbach, K. D., \& Kramer, R. M. (1996). Members' responses to organizational identity threats: Encountering and countering the Business Week rankings. Administrative Science Quarterly, 41, 442-476.

Epitropaki, O., Kark, R., Mainemelis, C., \& Lord, R. G. (2017). Leadership and followership identity processes: A multilevel review. Leadership Quarterly, 28, 104-129.

Epitropaki, O., Sy, T., Martin, R., Tram-Quon, S., \& Topakas, A. (2013). Implicit leadership and followership theories "in the wild": Taking stock of information-processing approaches to leadership and followership in organizational settings. The Leadership Quarterly, 24, 858-881.

*Fielding, K. S., \& Hogg, M. A. (1997). Social identity, self-categorization, and leadership: A field study of small interactive groups. Group Dynamics: Theory, Research, and Practice, 1, 39-51.

Fletcher, T. D. (2012). QuantPysc: Quantitative Psychology Tools (R version 1.5) [computer software]. Retrieved from https://CRAN.R-project.org/package=QuantPsyc.

*Fransen, K. (2017). Embodying who we are: How the perceived quality of athlete leaders is related to their perceived prototypicality [Data file]. Belgium: Fransen, K.

Fransen, K., Vanbeselaere, N., De Cuyper, B., Vande Broek, G., \& Boen, F. (2014). The myth of the team captain as principal leader: Extending the athlete leadership classification within sport teams. Journal of Sports Sciences, 32, 1389-1397.

*Gaffney, A. M., Sherburne, B., Hackett, J. D., Rast III, D. E., \& Hohman, Z. P. (2019). The transformative and informative nature of elections: Representation, schism, and exit. British Journal of Social Psychology, 58, 88-104.

*Gerpott, F. H., Van Quaquebeke, N., Schlamp, S., \& Voelpel, S. C. (2019). An identity perspective on ethical leadership to explain organizational citizenship behavior: the interplay of follower moral identity and leader group prototypicality. Journal of Business Ethics, 156, 1063-1078.

*Giessner, S. R., \& van Knippenberg, D. (2008). "License to Fail": Goal definition, leader group prototypicality, and perceptions of leadership effectiveness after leader failure. Organizational Behavior and Human Decision Processes, 105, 14-35.

*Giessner, S. R., van Knippenberg, D., \& Sleebos, E. (2009). License to fail? How leader group prototypicality moderates the effects of leader performance on perceptions of leadership effectiveness. Leadership Quarterly, 20, 434-451.

*Gleibs, I. H., \& Haslam, S. A. (2016). Do we want a fighter? The influence of group status and the stability of intergroup relations on leader prototypicality and 
endorsement. The Leadership Quarterly, 27, 557-573.

*Göncü, A. (2011). Leader group prototypicality and followers' identification: Predictors, mediating processes and follower outcomes [Doctoral dissertation]. Retrieved from Middle East Technical University ODTÜ Library. HM1261.G57.2011.

*Grille, A., Schulte, E. M., \& Kauffeld, S. (2015). Promoting shared leadership: A multilevel analysis investigating the role of prototypical team leader behavior, psychological empowerment, and fair rewards. Journal of Leadership \& Organizational Studies, 22, 324-339.

*Hains, S. C., Hogg, M. A., \& Duck, J. M. (1997). Self-categorization and leadership: Effects of group prototypicality and leader stereotypicality. Personality and Social Psychology Bulletin, 23, 1087-1099.

*Halevy, N., Berson, Y., \& Galinsky, A. D. (2011). The mainstream is not electable: When vision triumphs over representativeness in leader emergence and effectiveness. Personality and Social Psychology Bulletin, 37, 893-904.

Haslam, S. A. (2001). Psychology in organizations: The social identity approach. London: Sage.

Haslam, S. A., Jetten, J., Postmes, T., \& Haslam, C. (2009). Social identity, health and wellbeing: An emerging agenda for applied psychology. Applied Psychology: An International Review, 58, 1-23.

Haslam, S. A., \& Platow, M. J. (2001). The link between leadership and followership: How affirming social identity translates vision into action. Personality and Social Psychology Bulletin, 27, 1469-1479.

Haslam, S. A., Reicher, S. D., \& Platow, M. J. (2011). The new psychology of leadership: Identity, influence and power. London \& New York: Psychology Press.

Haslam, S. A., Reicher, S. D., \& Platow, M. J. (2015). Leadership. In J. D. Wright (Ed.), International Encyclopedia of the Social and Behavioral Sciences (2nd Ed, pp.648654). Oxford, UK: Elsevier.

Haslam, S. A., Steffens, N. K., Peters, P., Boyce, R. A., Mallett, C. J., \& Fransen, K. (2017). A social identity perspective on leadership development: The 5R Program. Journal of Personnel Psychology, 16, 113-124.

Haslam, S. A., \& Turner, J. C. (1992). Context-dependent variation in social stereotyping 2: The relationship between frame of reference, self-categorization and accentuation. European Journal of Social Psychology, 22, 251-277.

Haslam, S. A., Turner, J. C., Oakes, P. J., Reynolds, K. J., Eggins, R. A., Nolan, M., \& Tweedie, J. (1998). When do stereotypes become really consensual? Investigating the group-based dynamics of the consensualization process. European Journal of Social Psychology, 28, 755-776.

Hedges, L. V., Tipton, E., \& Johnson, M. C. (2010). Robust variance estimation in metaregression with dependent effect size estimates. Research Synthesis Methods, 1, 3965.

Hedges, L. V., \& Olkin, I. (1985). Statistical methods for meta-analysis. Orlando, FL: Academic Press.

Hedges, L. V., \& Vevea, J. L. (1998). Fixed-and random-effects models in meta-analysis. Psychological Methods, 3, 486-504.

*Hirst, G., van Dick, R., \& van Knippenberg, D. (2009). A social identity perspective on leadership and employee creativity. Journal of Organizational Behavior, 30, 963-982.

Hogg, M. A. (2001). A social identity theory of leadership. Personality and Social Psychology Review, 5, 184-200.

*Hogg, M. A., Fielding, K. S., Johnson, D., Masser, B., Russell, E., \& Svensson, A. (2006). Demographic category membership and leadership in small groups: A social identity 
analysis. Leadership Quarterly, 17, 335-350.

*Hogg, M. A., Hains, S. C., \& Mason, I. (1998). Identification and leadership in small groups: Salience, frame of reference, and leader stereotypicality effects on leader evaluations. Journal of Personality and Social Psychology, 75, 1248-1263.

Hogg, M. A., \& Terry, D. J. (2000). Social identity and self-categorization processes in organizational contexts. Academy of Management Review, 25, 121-140.

Hogg, M., \& van Knippenberg, D. (2003). Social identity and leadership processes in groups. Advances in Experimental Social Psychology, 35, 1-52.

Hogg, M. A., van Knippenberg, D., \& Rast, D. E. (2012). The social identity theory of leadership: Theoretical origins, research findings, and conceptual developments. European Review of Social Psychology, 23, 258-304.

Hollenbeck, J. R., Beersma, B., \& Schouten, M. E. (2012). Beyond team types and taxonomies: A dimensional scaling conceptualization for team description. Academy of Management Review, 37, 82-106.

Hollander, E. P., \& Julian, J. W. (1969). Contemporary trends in the analysis of leadership processes. Psychological Bulletin, 71, 387-397.

House, R., Javidan, M., \& Dorfman, P. (2001). Project GLOBE: An introduction. Applied Psychology, 50, 489-505.

*Hussain, S., \& Shahzad, K. (2018). Moderating Role of Supervisor's Organizational Embodiment on Leader-Member Exchange and Employee's Attitudinal and Behavioral Outcomes Relationships through Organizational Identification: A Test of Moderated Mediation Model Using Social Identity Theory. [Doctoral dissertation]. Riphah International University.

*Janson, A., Levy, L., Sitkin, S. B., \& Lind, E. A. (2008). Fairness and other leadership heuristics: A four-nation study. European Journal of Work and Organizational Psychology, 17, 251-272.

Judge, T. A., Bono, J. E., Ilies, R., \& Gerhardt, M. W. (2002). Personality and leadership: A qualitative and quantitative review. Journal of Applied Psychology, 87, 765-780.

Junker, N. M., \& van Dick, R. (2014). Implicit theories in organizational settings: A systematic review and research agenda of implicit leadership and followership theories. The Leadership Quarterly, 25, 1154-1173.

Kaiser, R. B., Hogan, R., \& Craig, S. B. (2008). Leadership and the fate of organizations. American Psychologist, 63, 96-110.

*Kalshoven, K., \& Den Hartog, D. N. (2009). Ethical leader behavior and leader effectiveness: The role of prototypicality and trust. International Journal of Leadership Studies, 5, 102-120.

Kepes, S., Banks, G. C., McDaniel, M., \& Whetzel, D. L. (2012). Publication bias in the organizational sciences. Organizational Research Methods, 15, 624-662.

*Koivisto, S. (2013). Supervisor's fair treatment and decision making in an organizational context - A social identity analysis [Doctoral dissertation]. Retrieved from Aalto University https://aaltodoc.aalto.fi/handle/123456789/10248

*Koivisto, S., \& Lipponen, J. (2015). A leader's procedural justice, respect and extra-role behaviour: The roles of leader in-group prototypicality and identification. Social Justice Research, 28, 187-206.

*Koivisto, S., Lipponen, J., \& Platow, M. J. (2013). Organizational and supervisory justice effects on experienced threat during change: The moderating role of leader in-group representativeness. Leadership Quarterly, 24, 595-607.

*Koivisto, S., \& Rice, R. E. (2016). Leader prototypicality moderates the relation between access to flexible work options and employee feelings of respect and leader endorsement. The International Journal of Human Resource Management, 27, 2771- 
2789.

Kühberger, A., Fritz, A., \& Scherndl, T. (2014). Publication bias in psychology: A diagnosis based on the correlation between effect size and sample size. PloS one, 9, e105825.

Lee, E. S., Park, T. Y., \& Koo, B. (2015). Identifying organizational identification as a basis for attitudes and behaviors: A meta-analytic review. Psychological Bulletin, 141, 1049-1080.

*Lehmann, A., \& Arnhold, M. C. (2013). Leader-member exchange and affective supervisor commitment: how does supervisor's organizational embodiment influence the relationship? [Master's thesis]. Retrieved from Norwegian Business School Open Archive. http://hdl.handle.net/11250/95016.

*Leicht, C., Randsley de Moura, G. R., \& Crisp, R. J. (2014). Contesting gender stereotypes stimulates generalized fairness in the selection of leaders. Leadership Quarterly, 25, 1025-1039.

*León, J. A. M., Cantisano, G. T., \& Mangin, J. P. L. (2009). Leadership in nonprofit organizations of Nicaragua and El Salvador: A study from the social identity theory. The Spanish Journal of Psychology, 12, 667-676.

*Li, N., Chiaburu, D. S., Kirkman, B. L., \& Xie, Z. (2013). Spotlight on the followers: An examination of moderators of relationships between transformational leadership and subordinates' citizenship and taking charge. Personnel Psychology, 66, 225-260.

*Lipponen, J., Koivisto, S., \& Olkkonen, M. E. (2005). Procedural justice and status judgements: The moderating role of leader ingroup prototypicality. Leadership Quarterly, 16, 517-528.

*Lipponen, J., Steffens, N. K., \& Holtz, B. C. (2018). Prototypical supervisors shape lay-off victims' experiences of top management justice and organizational support. Journal of Occupational and Organizational Psychology, 91, 158-180.

Lipsey, M. W., \& Wilson, D. B. (2001). Practical meta-analysis. London, England: SAGE.

Lord, R. G., Brown, D. J., \& Freiberg, S. J. (1999). Understanding the dynamics of leadership: The role of follower self-concepts in the leader/follower relationship. Organizational Behavior and Human Decision Processes, 78, 167-203.

Lord, R. G., Foti, R. J., \& De Vader, C. L. (1984). A test of leadership categorization theory: Internal structure, information processing, and leadership perceptions. Organizational Behavior and Human Performance, 34, 343-378.

*Marshall, J. A. (2012). Ethical leadership, prototypicality, integrity, trust, and leader effectiveness [Doctoral dissertation]. Retrieved from ProQuest Dissertation Publishing, 2012. 3515409.

Mavor, K. I., Platow, M. J., \& Bizumic, B. (Eds.). (2017). Self and social identity in educational contexts. Oxon \& New York: Routledge.

Moeyaert, M., Ugille, M., Natasha Beretvas, S., Ferron, J., Bunuan, R., \& Van den Noortgate, W. (2017). Methods for dealing with multiple outcomes in meta-analysis: A comparison between averaging effect sizes, robust variance estimation and multilevel meta-analysis. International Journal of Social Research Methodology, 20, 559-572.

Moher, D., Liberati, A., Tetzlaff, J., Altman, D. G., \& Prisma Group. (2009). Preferred reporting items for systematic reviews and meta-analyses: the PRISMA statement. PLoS Medicine, 6, e1000097.

*Mühlemann, N. (2017). Leader prototypicality and leader effectiveness in a foreign owned company in China [Data file]. Location: Mühlemann, $\mathrm{N}$.

*Mühlemann, N. (2017). Leader prototypicality and leader effectiveness in times of change [Data file]. Location: Mühlemann, N.

Ng, T. W. (2015). The incremental validity of organizational commitment, organizational 
trust, and organizational identification. Journal of Vocational Behavior, 88, 154-163.

Oakes, P. J., Haslam, S. A., \& Turner, J. C. (1994). Stereotyping and social reality. Oxford,

UK: Blackwell.

Packer, D. J. (2008). On being both with us and against us: A normative conflict model of dissent in social groups. Personality and Social Psychology Review, 12, 50-72.

Paterson, T. A., Harms, P. D., Steel, P., \& Credé, M. (2016). An assessment of the magnitude of effect sizes evidence from 30 years of meta-analysis in management. Journal of Leadership and Organizational Studies, 23, 66-81.

Peterson, R. A., \& Brown, S. P. (2005). On the use of beta coefficients in meta-analysis. Journal of Applied Psychology, 90, 175-181.

*Pierro, A., Cicero, L., Bonaiuto, M., van Knippenberg, D., \& Kruglanski, A. W. (2005). Leader group prototypicality and leadership effectiveness: The moderating role of need for cognitive closure. Leadership Quarterly, 16, 503-516.

*Pierro, A., Cicero, L., Bonaiuto, M., van Knippenberg, D., \& Kruglanski, A. W. (2007). Leader group prototypicality and resistance to organizational change: The moderating role of need for closure and team identification. Testing, Psychometrics, Methodology in Applied Psychology, 14, 27-40.

*Pierro, A., Cicero, L., \& Higgins, E. T. (2009). Followers' satisfaction from working with group-prototypic leaders: Promotion focus as moderator. Journal of Experimental Social Psychology, 45, 1105-1110.

Platow, M. J., Haslam, S. A., Reicher, S. D., \& Steffens, N. K. (2015). There is no leadership if no one follows: Why leadership is necessarily a group process. International Coaching Psychology Review, 10, 20-37.

*Platow, M. J., \& van Knippenberg, D. (2001). A social identity analysis of leadership endorsement: The effects of leader ingroup prototypicality and distributive intergroup fairness. Personality and Social Psychology Bulletin, 27, 1508-1519.

*Platow, M. J., van Knippenberg, D., Haslam, S. A., van Knippenberg, B., \& Spears, R. (2006). A special gift we bestow on you for being representative of us: Considering leader charisma from a self-categorization perspective. British Journal of Social Psychology, 45, 303-320.

Podsakoff, P. M., \& Podsakoff, N. P. (2019). Experimental designs in management and leadership research: Strengths, limitations, and recommendations for improving publishability. Leadership Quarterly, 30, 11-33.

Postmes, T. \& Haslam, S. A, \& Swaab, R. (2005). Social influence in small groups: An interactive model of identity formation. European Review of Social Psychology, 16, $1-42$.

R Core Team (2016). R: A language and environment for statistical computing (Version 3.6.1). Vienna, Austria, R: Foundation for Statistical Computing. Retrieved 16 June 2017 from https://www.r-project.org.

*Rast III, D. E., Gaffney, A. M., Hogg, M. A., \& Crisp, R. J. (2012). Leadership under uncertainty: When leaders who are non-prototypical group members can gain support. Journal of Experimental Social Psychology, 48, 646-653.

*Rast III, D. E., Hogg, M. A., \& Giessner, S. R. (2013). Self-uncertainty and support for autocratic leadership. Self and Identity, 12, 635-649.

*Rast III, D. E., Hogg, M. A., \& Tomory, J. J. (2015). Prototypical leaders do not always get our support: Impact of self-uncertainty and need for cognition. Self and Identity, 14, 135-146.

Raudenbush, S. W. (2009). Analyzing effect sizes: Random effects models. In: Cooper, H., Hedges, L. V, \& Valentine, J. C. (Eds.), The handbook of research synthesis and meta-analysis (2nd ed., pp. 295-315). New York: Russell Sage Foundation. 
Reicher, S. D., Haslam, S. A., \& Hopkins, N. (2005). Social identity and the dynamics of leadership: Leaders and followers as collaborative agents in the transformation of social reality. Leadership Quarterly, 16, 547-568.

Reicher, S. D., \& Hopkins, N. (2001). Self and nation: Categorization, contestation and mobilization. London: Sage.

Riketta, M., \& van Dick, R. (2005). Foci of attachment in organizations: A meta-analytic comparison of the strength and correlates of workgroup versus organizational identification and commitment. Journal of Vocational Behavior, 67, 490-510.

*Riyadi, N., Asakarunia, D. A., Wijaya, F., \& Riantoputra, C. D. (2019). The Construction of Positive Leader Identity: Acquiring a Leadership Position and Being Accepted by Others. In Leading for High Performance in Asia (pp. 65-88). Springer, Singapore.

Rosch, E. (1978). Principles of categorization. In E. Rosch \& B. B. Lloyd (Eds), Cognition and categorization (pp. 27-48). Hillsdale, New Jersey: Lawrence Erlbaum Associates.

Rosenthal, R. (1991). Meta-analytic procedures for social research. Newpark CA: Sage.

*Rothers, A. (2016). Fair enough? Gender-specific evaluations of distributely fair and unfair leaders in intergroup context [Master's thesis]. University of Hamburg, Hamburg, Germany.

RStudio Team (2016). RStudio: Integrated Development for R. RStudio, Inc. (Version 1.1.463). Boston, MA. Retrieved 16 June 2017 from http://www.rstudio.com.

Sani, F. (2008). Schism in groups: A social psychological account. Social and Personality Psychology Compass, 2, 718-732.

Schielzeth, H. (2010). Simple means to improve the interpretability of regression coefficients. Methods in Ecology and Evolution, 1, 103-113.

Schmidt, F. L., \& Oh, I. S. (2016). The crisis of confidence in research findings in psychology: Is lack of replication the real problem? Or is it something else? Archives of Scientific Psychology, 4, 32-36.

*Scott, F. C. (2017). Leader Group Prototypicality and Follower Job Satisfaction: The Moderating Role of Leader Fairness. East Carolina University. [Master's thesis]. East Carolina University.

*Seppälä, T., Lipponen, J., \& Pirttilä-Backman, A. M. (2012). Leader fairness and employees' trust in coworkers: The moderating role of leader group prototypicality. Group Dynamics: Theory, Research, and Practice, 16, 35-49.

Shamir, B., House, R. J., \& Arthur, M. B. (1993). The motivational effects of charismatic leadership: A self-concept based theory. Organization Science, 4, 577-594.

Shamir, B., \& Howell, J. M. (1999). Organizational and contextual influences on the emergence and effectiveness of charismatic leadership. Leadership Quarterly, 10, 257-283.

*Shoss, M. K., Eisenberger, R., Restubog, S. L. D., \& Zagenczyk, T. J. (2013). Blaming the organization for abusive supervision: The roles of perceived organizational support and supervisor's organizational embodiment. Journal of Applied Psychology, 98, 158168.

*Sluss, D. M. (2006). Generalizing relational identification to and from organizational identification [Doctoral dissertation]. Arizona State University, Arizona, United States of America.

*Sluss, D. M., Ployhart, R. E., Cobb, M. G., \& Ashforth, B. E. (2012). Generalizing newcomers' relational and organizational identifications: Processes and prototypicality. Academy of Management Journal, 55, 949-975.

Stam, D., Lord, R. G., van Knippenberg, D., \& Wisse, B. (2014). An image of who we might become: Vision communication, possible selves, and vision pursuit. Organization Science, 25, 1172-1194. 
*Steffens, N. K. (2012). Leaders' personal performance and prototypicality as interactive determinants of social identity advancement [Doctoral dissertation]. Retrieved from Open Research Exeter. http://hdl.handle.net/10036/3656.

*Steffens, N. K., Haslam, S. A., \& Reicher, S. D. (2014). Up close and personal: Evidence that shared social identity is a basis for the 'special' relationship that binds followers to leaders. Leadership Quarterly, 25, 296-313.

*Steffens, N. K., Haslam, S. A., Reicher, S. D., Platow, M. J., Fransen, K., Yang, J., Ryan, M. K., Jetten, J., Peters, K., \& Boen, F. (2014). Leadership as social identity management: Introducing the Identity Leadership Inventory (ILI) to assess and validate a four-dimensional model. Leadership Quarterly, 25, 1001-1024.

*Steffens, N. K., Haslam, S. A., Ryan, M. K., \& Kessler, T. (2013). Leader performance and prototypicality: Their inter-relationship and impact on leaders' identity entrepreneurship. European Journal of Social Psychology, 43, 606-613.

Steffens, N. K., Haslam, S. A., Schuh, S. C., Jetten, J., \& van Dick, R. (2017). A metaanalytic review of social identification and health in organizational contexts. Personality and Social Psychology Review, 21, 303-335.

*Steffens, N. K., Schuh, S. C., Haslam, S. A., Perez, A., \& van Dick, R. (2015). 'Of the group'and 'for the group': How followership is shaped by leaders' prototypicality and group identification. European Journal of Social Psychology, 45, 180-190.

Sterne, J. A. C., \& Egger, M. (2005). Regression methods to detect publication and other bias in meta-analysis. In: Rothstein, H. R., Sutton, A. J., \& Borenstein, M (Eds.), Publication bias in meta-analysis: prevention, assessment, and adjustments (pp. 99110.) Chichester, UK: John Wiley \& Sons.

*Stevens, M., Rees, T., Coffee, P., Haslam, S. A., Steffens, N. K., \& Polman., R. (2017). Social identity leadership, physical activity and health-related outcomes: A crosssectional study. Manuscript in preparation.

*Su, W., Lin, X., \& Ding, H. (2019). The Influence of Supervisor Developmental Feedback on Employee Innovative Behavior: A Moderated Mediation Model. Frontiers in psychology, 10, 1-12.

*Sucharski, I. L. (2007). Influencing employees' generalization of support and commitment from supervisor to organization [Doctoral dissertation]. ProQuest Dissertations Publishing, 2007. 3247693.

*Sugita, L., \& Zhao, Z. (2017). Flexible Working Arrangement: Exploring leader prototypicality, endorsement, and employee's respect in SMEs. [Master's thesis]. East Carolina University. Linköping University.

Tajfel, H., \& Turner, J. C. (1979). An integrative theory of intergroup conflict. In W. G. Austin \& S. Worchel (Eds). The social psychology of intergroup relations. Monterey, CA: Brooks / Cole.

*Tavares, G. M., Concatto, F. M., \& Sobral, F. (2017). Being true to who we are: Group prototypicality, authenticity and leadership emergence endorsement. Manuscript in preparation.

*Tee, E. Y., Ng, Y. L., \& Paulsen, N. (2014). To be one of us, you have to feel like one of us: How leaders' expressed emotions influence followers' perceptions of leader selfsacrifice intentions and effectiveness in a crisis situation. In N. M. Ashkanasy, W. J. Zerbe, \& C. E. J. Hätel (Eds.), Emotions and the Organizational Fabric (Research on Emotion in Organizations, Volume 10) Emerald Publishing Limited (pp. 247-270).

Thomas, E. F., Amiot, C. E., Louis, W. R., \& Goddard, A. (2017). Collective selfdetermination: How the agent of help promotes pride, well-being, and support for intergroup helping. Personality and Social Psychology Bulletin, 43, 662-677.

Turner, J. C. (1985). Social categorization and the self-concept: A cognitive theory of group 
behaviour. In E. J. Lawler (Ed.), Advances in group processes (pp. 77-122). Greenwich CT US: JAI Press.

Turner, J. C. (1982). Towards a redefinition of the social group. In H. Tajfel (Ed.), Social Identity and Intergroup Relations (pp. 15-40). Cambridge: Cambridge University Press.

Turner, J. C. (1991). Social influence. Milton Keynes, UK: Open University Press.

Turner, J. C., \& Haslam, S. A. (2001). Social identity, organizations, and leadership. In M. E. Turner (Ed.), Groups at work: Theory and research (pp. 25-65). Mahwah, NJ US: Lawrence Erlbaum Associates Publishers.

Turner, J. C., Hogg, M. A., Oakes, P. J., Reicher, S. D., \& Wetherell, M. S. (1987). Rediscovering the social group: A self-categorization theory. Cambridge, MA, US: Blackwell.

Turner, J. C., Oakes, P. J., Haslam, S. A., \& McGarty, C. (1994). Self and collective: Cognition and social context. Personality and Social Psychology Bulletin, 20, 454463.

*Ullrich, J., Christ, O., \& van Dick, R. (2009). Substitutes for procedural fairness: Prototypical leaders are endorsed whether they are fair or not. Journal of Applied Psychology, 94, 235-244.

Van den Noortgate, W., López-López, J. A., Marín-Martínez, F., \& Sánchez-Meca, J. (2014). Meta-analysis of multiple outcomes: A multilevel approach. Behavior Research Methods, 47, 1274-1294.

Van den Noortgate, W., \& Onghena, P. (2003). Multilevel meta-analysis: A comparison with traditional meta-analytical procedures. Educational and Psychological Measurement, 63, 765-790.

van Dick, R., Kerschreiter, R., Steffens, N. K., Akfirat, S.A., Dumont, K., et al. (2018). Identity leadership going global: Validation of the identity leadership inventory across 20 countries. Journal of Occupational and Organizational Psychology, 91, 697-728.

*Van Dick, R., Lemoine, J. E., Steffens, N. K., Kerschreiter, R., Akfirat, S. A., Avanzi, L., ... \& González, R. (2018). Identity leadership going global: Validation of the Identity Leadership Inventory across 20 countries. Journal of Occupational and Organizational Psychology, 91, 697-728.

*van Dijke, M., \& De Cremer, D. (2008). How leader prototypicality affects followers' status: The role of procedural fairness. European Journal of Work and Organizational Psychology, 17, 226-250.

*van Dijke, M., \& De Cremer, D. (2010). Procedural fairness and endorsement of prototypical leaders: Leader benevolence or follower control? Journal of Experimental Social Psychology, 46, 85-96.

van Knippenberg, D. (2000). Work motivation and performance: A social identity perspective. Applied Psychology, 49, 357-371.

van Knippenberg, D. (2011). Embodying who we are: Leader group prototypicality and leadership effectiveness. Leadership Quarterly, 22, 1078-1091.

van Knippenberg, D. (2012). Leadership: A person-in situation perspective. In K. Deaux \& M. Snyder (Eds.), The oxford handbook of personality and social psychology (pp. 673-700). New York: Oxford University Press.

van Knippenberg, D. (2020). Meaning-based leadership. Organizational Psychology Review, 10, 6-28.

van Knippenberg, D., \& Hogg, M. A. (2003). A social identity model of leadership effectiveness in organizations. Research in Organizational Behavior, 25, 243-295.

*van Knippenberg, B., \& van Knippenberg, D. (2005). Leader self-sacrifice and leadership effectiveness: The moderating role of leader prototypicality. Journal of Applied 
Psychology, 90, 25-37.

*van Knippenberg, D., van Knippenberg, B., \& De Cremer, D. (2005). Extending the social identity model of leadership: The interactive effect of leader prototypicality and leader procedural fairness. Paper presented at the General Meeting of the European Association of Work \& Organizational Psychology, Istanbul, May 2005.

van Knippenberg, D., van Knippenberg, B., De Cremer, D., \& Hogg, M. A. (2004). Leadership, self, and identity: A review and research agenda. Leadership Quarterly, 15, 825-856.

van Knippenberg, D., van Knippenberg, B., \& van Dijk, E. (2000). Who takes the lead in risky decision making? Effects of group members' individual riskiness and prototypicality. Organizational Behavior and Human Decision Processes, 83, 213 234.

van Quaquebeke, N., Graf, M. M., \& Eckloff, T. (2014). What do leaders have to live up to? Contrasting the effects of central tendency versus ideal-based leader prototypes in leader categorization processes. Leadership, 10, 191-217.

van Vugt, M., Hogan, R., \& Kaiser, R. B. (2008). Leadership, followership, and evolution: some lessons from the past. American Psychologist, 63, 182-196.

Venus, M., Stam, D., \& van Knippenberg, D. (2019). Visions of change as visions of continuity. Academy of Management Journal. Advance online publication. doi: 10.5465/amj.2015.1196

Viechtbauer, W. (2005). Bias and efficiency of meta-analytic variance estimators in the random effects model. Journal of Educational and Behavioral Statistics, 30, 261-293.

Viechtbauer, W. (2010). Conducting meta-analyses in R with the metafor package. Journal of Statistical Software, 36, 1-48.

Viechtbauer, W. (2016). Meta-analysis package for $R$ (Version 2.4-0) [PDF file]. Retrieved 15 June 2020 from https://cran.r-project.org/web/packages/metafor/metafor.pdf.

*Wang, D. (2016). The Buck Stops Where? Examining Leader and Collective Accountability in Teams [Doctoral dissertation]. Retrieved from Arizona State University Digital Repository. https://repository.asu.edu/items/38399.

*Wu, H. (2009). Transformational leadership and outcomes: role of supervisor's organizational embodiment [Master's thesis]. Retrieved from University of Delaware Library. http://udspace.udel.edu/handle/19716/5459.

*Xiang, N. (2009). Just because you lead us, it doesn't mean we have to like you: How can anti-norm leaders mitigate negative evaluations from their group members? [Doctoral dissertation]. Retrieved from The University of Queensland eSpace. https://espace.library.ud.edu.au/view/UQ:205159.

Wenzel, M., Mummendey, A., \& Waldzus, S. (2008). Superordinate identities and intergroup conflict: The ingroup projection model. European Review of Social Psychology, 18, 331-372.

Westfall, J. (2015). Follow-up: What about Uri's 2n rule? [Blog post]. Retrieved 24 May 2019 from http://jakewestfall.org/blog/index.php/2015/05/27/follow-up-what-abouturis-2n-rule/\#comment-24.

Wheelan, S. A., \& Johnston, F. (1996). The role of informal member leaders in a system containing formal leaders. Small Group Research, 27, 33-55.

Wickham. H. (2011). The split-apply-combine strategy for data analysis. Journal of Statistical Software, 40, 1-29. 


\section{Figures and Tables}

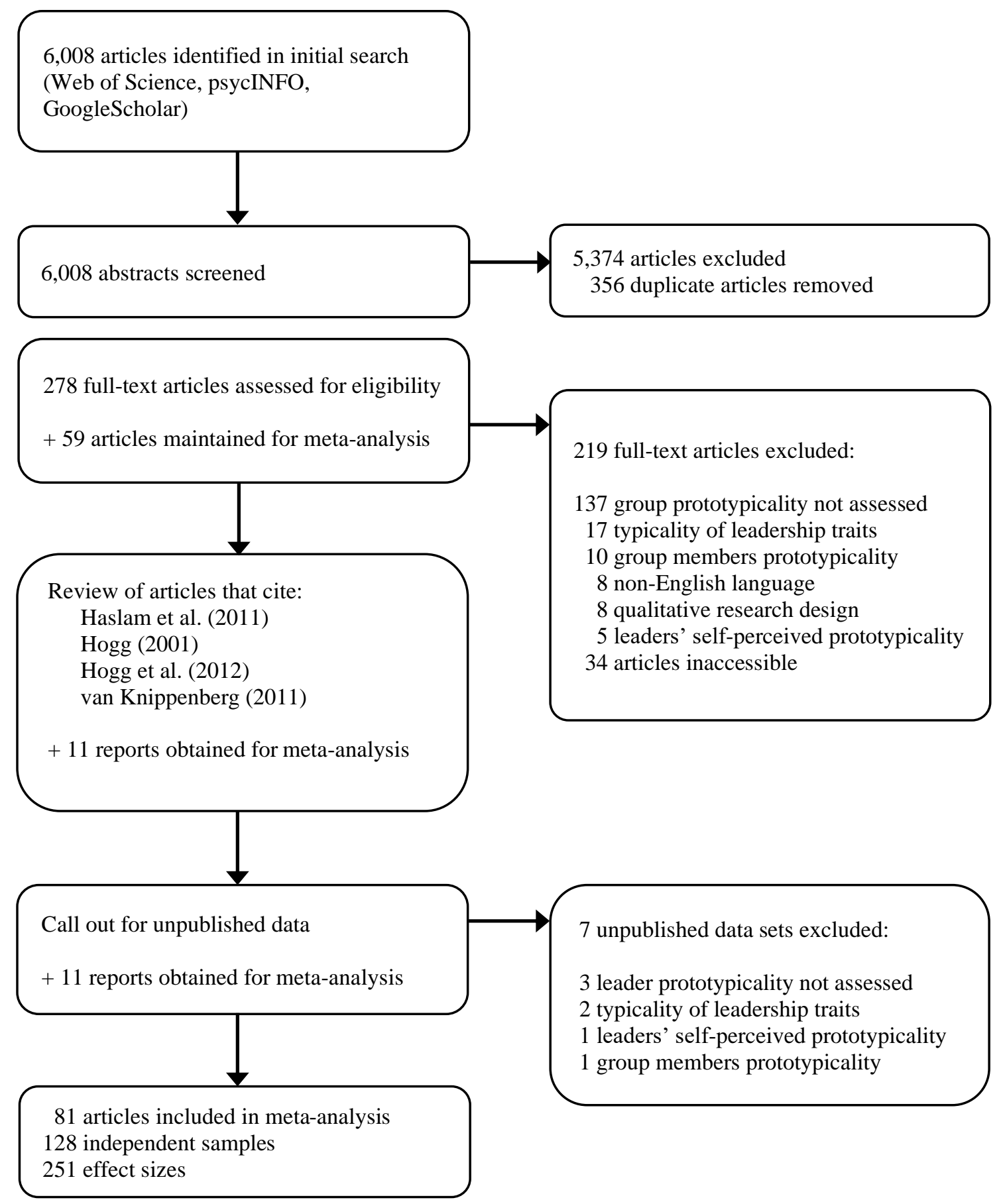

Figure 1. Flow diagram displaying process of identification and selection of relevant studies. 
Table 1. Common scales assessing leader group prototypicality.

Scale Name (Reference)
$\begin{aligned} & \text { Leader Relative Ingroup Prototypical } \\ & \text { Scale } \\ & \text { (Platow \& van Knippenberg, 2001) }\end{aligned}$
Leader Group Prototypicality Scale
(van Knippenberg \& van Knippenberg,

(van Knippenberg \& van Knippenberg, 2005)

Identity Leadership Inventory-Leader Identity Prototypicality Subscale

(Steffens et al., 2014)

Supervisor Organizational Embodiment Scale

(Eisenberger et al., 2010)

\section{$k$}

49

This leader] represents what is characteristic about [in-group]

2. [This leader] is representative of [in-group] members.

3. [This leader] is a good example of the kind of people who are members of [in-group].

4. [This leader] stands for what members of [in-group] have in common.

5. [This leader] is not representative of the kind of people who are members of [in-group]. (reversed)

6. [This leader] is very similar to most people in [in-group].

36 1. [This leader] is a good example of the kind of people that are members of [in-group].

2. [This leader] represents what is characteristic about [in-group].

3. [This leader] has a lot in common with members of [in-group].

4. [This leader] is very similar to the members of [in-group].

5. [This leader] represents what [in-group] stands for.

6. [This leader] is an embodiment of our [in-group] group norms.

33 1. [This leader] embodies what it means to be a member of [in-group].

2. [This leader] is representative of members of [in-group].

3. [This leader] is model member of [in-group].a

4. [This leader] exemplifies what it means to be a member of [in-group].a

25 1. When [this leader] encourages me, I believe that [in-group] is encouraging me.

2. When [this leader] is pleased with my work, I feel that [in-group] is pleased.

3. When [this leader] compliments me, it is the same as [in-group] complimenting me.

4. When [this leader] pays attention to my efforts, I believe that [in-group] is paying attention to my efforts.

5. [This leader] is characteristic of [in-group].

6. [This leader] and [in-group] have a lot in common.

7. When I am evaluated by [this leader], it is the same as being evaluated by [in-group].

8. [This leader] is representative of [in-group].

9. [This leader] is typical of [in-group].

Sample of other residual (less common) scales assessing leader group protptypicality

Leader Group Prototypicality Scale created for purpose of study

(Janson et al., 2008): Study 2)
1 1. In terms of interests and values, [this leader] does not have a lot in common with the team. (reversed)

2. [This leader] is a great fit for the team.

3. [This leader] exemplifies what is best about the team.a 
Leader Group Prototypicality Scale created for purpose of study

(León et al., 2009)

Leader Group Prototypicality Scale created for purpose of study

(Sluss, 2006)
1 1. [This leader] represents the most characteristic traits of the group.

2. [This leader] would be elected by the group members to represent the group before others.

3. [This leader] is well-liked by the group members.

4. [This leader] personifies the most positive values of the group.a

1 1. [This leader] is an exemplary member of the organization.a

2. [This leader] acts according to the organizational goals and values.a

3. [This leader] represents what the organization stands for.

Note. $k=$ number of independent samples that used a given scale; a indicates items assessing ideal-type notion of leader group prototypicality as coded in present analysis. The sixth item from van Knippenberg and van Knippenberg (2005) was used only in Study 4 and has not been used commonly in subsequent research. When researchers referenced both Platow and van Knippenberg (2001) and van Knippenberg and van Knippenberg (2005) as the scale they used, the effect size was coded as Platow and van Knippenberg (2001). 
Table 2. Intercorrelations between variables.

\begin{tabular}{lllllllll}
\hline Variable & 1 & 2 & 3 & 4 & 5 & 6 & 7 & 8 \\
\hline 1. Prototypicality & & & & & & & & \\
conceptualization & - & & & & & & \\
2. Intergroup context & $\mathrm{n} / \mathrm{a} a$ & - & & & & & \\
3. Prototype strength & .12 & .21 & - & & & & \\
4. Target leader & .22 & .14 & .53 & - & & & \\
5. Outcome index & -.01 & -.19 & .22 & .18 & - & & \\
6. Study methodology & .33 & $\mathrm{n} / \mathrm{ab}$ & .76 & .55 & .20 & - & & \\
7. Publication status & .29 & .39 & -.02 & .11 & -.08 & .03 & - & \\
8. Sample size & .28 & .03 & .18 & .11 & .12 & .15 & -.08 & - \\
\hline
\end{tabular}

Notes. All correlations based on 251 effect sizes $/ k=128$ except those pertaining to intergroup context which is based on 79 effect sizes $/ k=46 ; \mathrm{n} / \mathrm{a}=$ correlation cannot be calculated because the correlation pertains to two categorical variables where one variable of the pair falls within one level of the respective other; a all studies with information about intergroup context fall within average operationalizations; $b$ all studies with information about intergroup context are subsumed within experimental studies; Prototypicality conceptualization: $0=$ average, $1=$ ideal; Intergroup context: $0=$ implicit, $1=$ explicit; Prototype strength: $0=$ short-lived group, $1=$ enduring group; Target leader: $0=$ non-formal, $1=$ formal; Outcome index: $0=$ subjective indices, $1=$ behavioral indices; Study methodology: $0=$ experimental, $1=$ correlational/longitudinal.

$N$ for correlation is the lower $n$ of the pair. For $n=251$, all $r \geq|.15|$ significant at .05 level (twotailed); for $n=79$ (pertaining to intergroup context), all $r \geq|.39|$ significant at .05 level (twotailed). 
Table 3. Results of categorical moderation analyses of the relationship between leader group prototypicality and leadership outcomes.

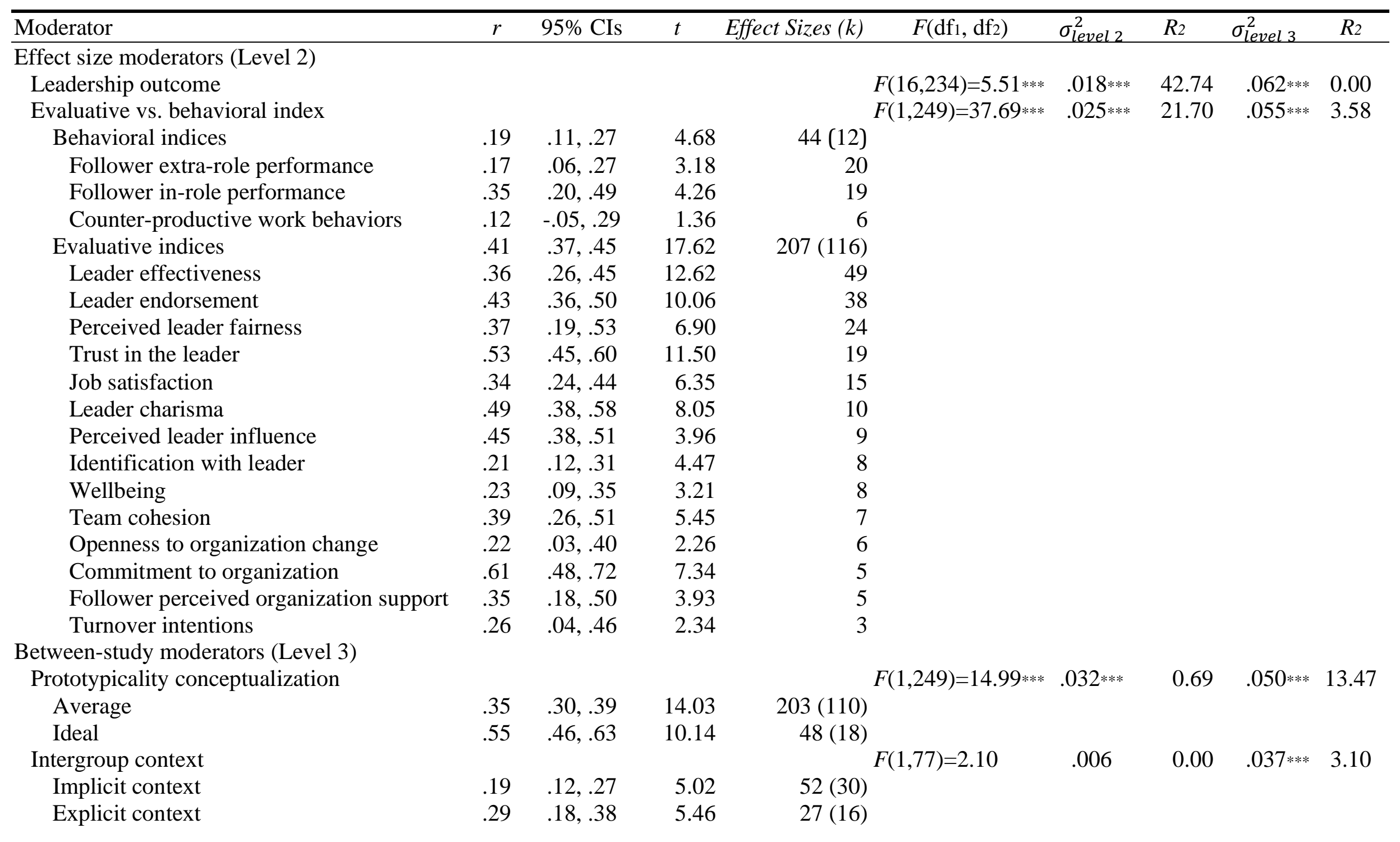


Prototype strength

Short-lived group

Enduring group

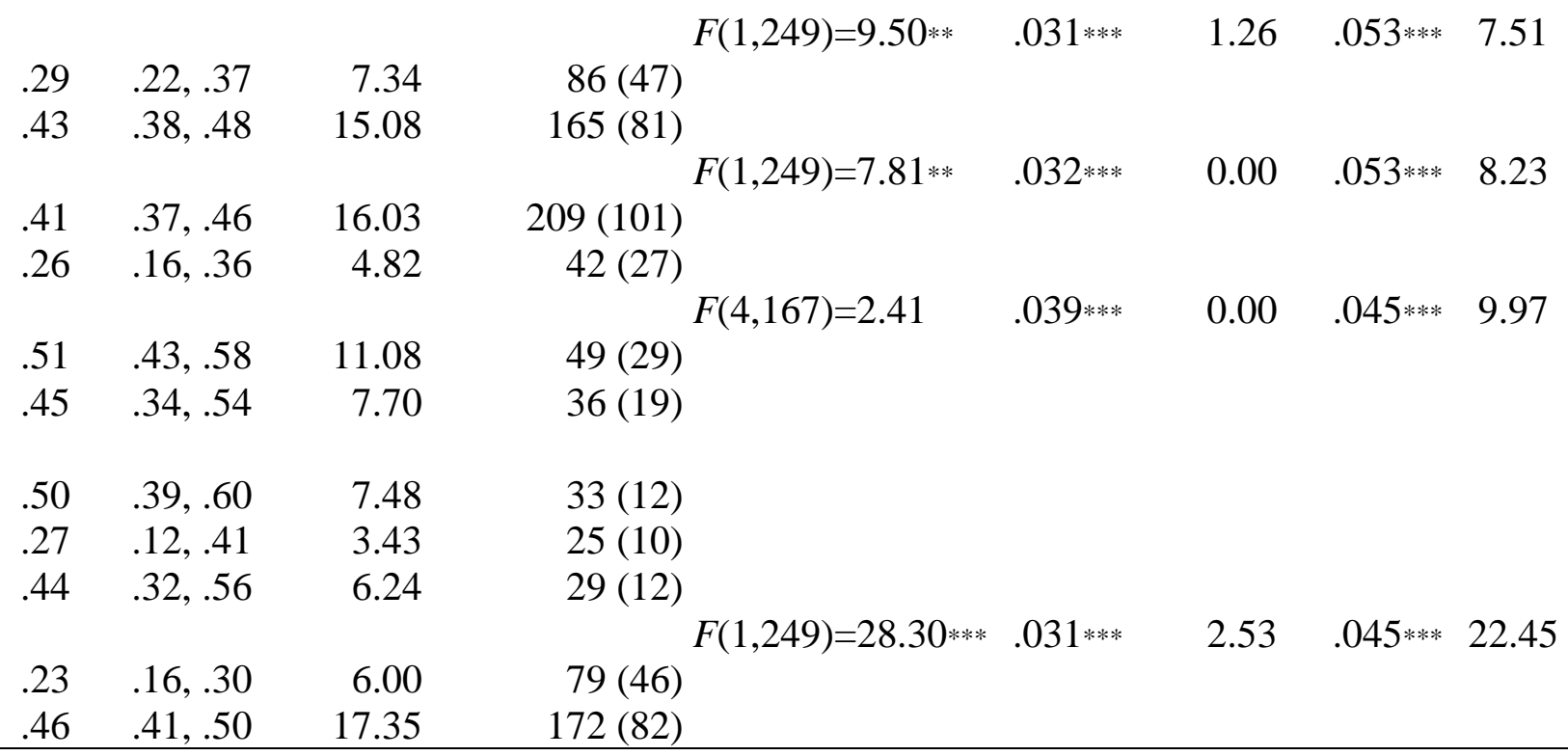

Leader role

Formal

Non-formal

Leader group prototypicality scale

Platow \& van Knippenberg (2001)

van Knippenberg \& van Knippenberg

(2005)

Steffens et al. (2014)

Eisenberger et al. (2010)

Residual others

Study methodology

Experimental

$41, .50$

17.35

Notes. $r=$ weighted sample size corrected correlation coefficient between leader group prototypicality and leader outcome; $95 \% \mathrm{CI}=$ lower and upper bounds of $95 \%$ confidence interval; $T=t$ value for coefficient when compared to zero; $k=$ number of effect sizes with the number in parentheses representing the number of studies; $\sigma_{2}=$ the variance not accounted for by the moderating variable at each level respectively; $F\left(\mathrm{df}_{1}, \mathrm{df}_{2}\right)=$ the test of heterogeneity between the levels of a moderating variable. ${ }^{*} p<.05 . * * p .01 . * * * p .001$. 